\title{
Interactions of titania based nanoparticles with silica and
}

\section{green-tea: photo -degradation and -luminescence}

\author{
Rajni Verma ${ }^{1}$, Aditi Awasthi ${ }^{1}$, Punita Singh ${ }^{1}$, Ritu Srivastava ${ }^{1}$, Huaping Sheng ${ }^{2}$, Jianguo Wen ${ }^{2}$, Dean \\ J. Miller ${ }^{2}$ and Avanish K. Srivastava* ${ }^{1}$ \\ ${ }^{1}$ Academy of Scientific and Innovative Research, CSIR - National Physical Laboratory, Dr. K. S. \\ Krishnan Road, New Delhi-110012, India \\ ${ }^{2}$ Electron Microscopy Center- Center for Nanoscale Materials, Argonne National Laboratory, \\ Argonne, IL 60439-4838, USA. \\ "Corresponding author. Tel: (91) 11 45609308; Fax: (91) 1145609310. \\ E-mail: aks@nplindia.org, avanish.aks555@gmail.com
}

\begin{abstract}
An effective way to modify the photocatalytic activity of both anatase and rutile $\mathrm{TiO}_{2}$ nanoparticles by coating the surface with either an inorganic $\left(\mathrm{SiO}_{2} /\right.$ silica) or organic (green-tea) layer using a chemical approach is demonstrated. Tetraethyl orthosilicate (TEOS) was used to cover the surface of $\mathrm{TiO}_{2}$ with silica which facilitates the inhibition of photocatalytic activity, ensuring its application in sunscreens by blocking the reactive oxygen species (ROS). Green- tea extract, rich in epigallocatechin gallate (EGCG), was used to coat/stabilize nano-sized $\mathrm{TiO}_{2}$. The morphology of these coatings was revealed by transmission electron microscopy (TEM) and by energy dispersive spectroscopy (EDS) mapping. These studies showed good coverage for both types of coating, but with somewhat better uniformity of the coating layer on rutile $\mathrm{TiO}_{2}$ compared to anatase due to its more uniform particle geometry. The effectiveness of each coating was evaluated by photodegradation of an organic dye (methyl orange). These studies showed rutile_polyphenol exhibits the highest photocatalytic activity among rutile forms which validates its feasibility to be used in photodegradation.
\end{abstract}

Keywords: $\mathrm{TiO}_{2}$ nanoparticles, silica, green-tea, photocatalytic activity, electron microscopy. 


\section{Introduction:}

$\mathrm{TiO}_{2}$ (titania) is attractive as a photocatalyst because of its high surface area, high absorption capability, slow rate of charge carrier recombination and biocompatibility [1]. As a result, a range of applications that rely on $\mathrm{TiO}_{2}$ have been developed including dye-sensitized solar cells (DSSCs) [2-3], effective photocatalytic activity [4-7] by the photodegradation of organic dyes [8-9], water purification [10], biological applications [11-12], antimicrobial activities $[13,14]$ and cosmetics $[15,16]$. Photodegradation of organic dyes is an application in which fast separation and spatial control of exciton pair is highly beneficial but for cosmetic application this behaviour is undesirable. It is reported that irradiation of UV light on $\mathrm{TiO}_{2}$ nanoparticles leads to the production of reactive oxygen species (ROS) which includes: (i) superoxide radical, (ii) hydroxyl radical and (iii) singlet oxygen, causing an adverse affect to all the types of organic biomolecules, including carbohydrates, proteins, nucleic acids, lipids and DNA [17-18]. Thus, the ability to manipulate the surface property is an extremely critical factor to optimize different phases of titania nanoparticles, anatase and rutile, for both these photorelated phenomena.

Surface modification of these materials has traditionally been achieved by coating the photocatalyst surface with ceramic and other oxide materials such as $\mathrm{SiO}_{2}, \mathrm{Al}_{2} \mathrm{O}_{3}, \mathrm{ZrO}_{2}, \mathrm{WO}_{3}, \mathrm{MoO}_{3}$ [19-20]. Utilization of organic materials for surface modification has typically involved bulk admixtures, which has been exploited successfully in the pigment industry [21-22] or the addition of antioxidants such as vitamin A, E, or C. Even though success has been achieved in both titania-based cosmetic applications and photocatalyst applications, a comparative study and understanding of the balance between these processes is yet to be fully realized.

For example, the intrinsic photocatalyst behavior may change when bulk admixtures are introduced. Organic surface coatings can be utilized to circumvent this effect. In addition, organic coatings offer other advantages compared to inorganic coatings. Surface modification of nanoparticles by organic coating provides good biocompatibility and biodegradability of the functional organic materials. It has also been reported that organic moiety provides various functional groups such as hydroxyl group, aldehydic group, carboxyl group and many others. These groups can be used to enhance chemical interactions to various biosubstances [23]. In addition, organic species are cheaper and naturally abundant as compared to inorganic species.

In the present work, we compared the effectiveness of a traditional inorganic coating, silica, to that of an organic coating derived from green tea (camellia sinensis). Green tea is a popular beverage because of health promoting effects and a pleasant aroma [24]. Owing to its low toxicity, biocompatibility and environmental friendly nature, 
it is used for "green" synthesis of nanoparticles [25]. Green tea also is antimutagenic, anti-inflammatory, antibacterial, antiproliferative and has strong natural antioxidant properties that are known to protect the skin from UV damage and prevent cellular damage caused by ROS generation [26-27] . Green tea is characterised by high content of catechins, a sub-class of flavan-3-ol (a flavonoid), having 20 times more potent antioxidant property than vitamin $\mathrm{C}$ in the lipoprotein oxidation model [28]. In general, the main constituent of green tea extract is polyphenols, predominantly the catechins [29-31]. The four major catechins are: (i) epicatechin (EC) (ii) epicatechin gallate (ECG) (iii) epigallocatechin (EGC) and (iv) epigallocatechin gallate (EGCG). Of the catechins, the main component found in green tea is EGCG [32]. EGCG contributes to the overall protection of cell integrity and immune function and also suppresses the growth of cancerous cells [24, 33]. EGCG is not only the good antioxidant but it also promotes anti-aging, anti-acne and anti-inflammatory effects, so it is an attractive component for use in cosmetics [34]. Green tea extract enhances the activity of enzyme superoxide dismutase (SOD) which helps to quench the excess superoxide radicals, peroxyl radicals, singlet oxygen and thus helps inhibiting the premature aging [35-36]. It is approximately $99 \%$ water, so it helps to maintain hydration, makes an important contribution to daily fluid requirement and thus helpful to remove the waste product from the body [37]. Also, the antioxidant action of polyphenols, found in green tea, is known to increase the antioxidant capacity of blood [38]. Thus, green tea extract was expected to be an attractive material for modifying the surface of photocatalysts [25, 39].

Herein, we studied coatings on two forms of $\mathrm{TiO}_{2}$ - anatase and rutile. The $\mathrm{TiO}_{2}$ nanoparticles can be produced by simple, efficient wet chemical method and then annealed at different temperatures. The products were then coated with either silica or by polyphenol from green tea extract. The effectiveness of each coating was evaluated by photodegradation of an organic dye (methyl orange). The samples were analyzed by various characterization techniques including XRD, FTIR, SEM/EDX, high resolution transmission electron microscopy (HR-TEM), high- angle annular dark-field scanning transmission electron microscopy (HAADF-STEM) and UV-Vis. We propose a mechanism for the chemical interaction at the surface of the titania particles and compare the photoluminescence spectra and photocatalytic capability of bare-, silica coated- and polyphenol coated- $\mathrm{TiO}_{2}$ nanoparticles at various time intervals.

\section{Experimental Section}

\subsection{Chemicals used}


The chemicals used in the synthesis of $\mathrm{TiO}_{2}$ nanoparticles were titanium tetra isopropoxide (TTIP, $\mathrm{Ti}\left(\mathrm{OCH}\left(\mathrm{CH}_{3}\right)_{2}\right)_{4}$, LR, 98\%, Spectrochem Pvt. Ltd., India), Absolute ethanol $\left(\mathrm{C}_{2} \mathrm{H}_{6} \mathrm{O}\right.$, AR, 99.9\%, S D FineChem Ltd., India), Methanol ( $\mathrm{CH}_{3} \mathrm{OH}$, HPLC grade, AR, 99.8\%, Rankem, India).

For coating with silica, polyvinyl alcohol (PVA, LR, 75\%, Central Drug House Pvt. Ltd., India), ammonia solution $\left(\mathrm{NH}_{3}, \mathrm{LR}, 25 \%\right.$, Rankem, India), tetraethyl orthosilicate (TEOS, $\mathrm{Si}\left(\mathrm{OC}_{2} \mathrm{H}_{5}\right)_{4}, \mathrm{LR}, 98 \%$, Otto, India) were used.

For coating with polyphenol, Lipton green tea was used. Millipore water (18 M $\Omega$ ) was used during the synthesis process and further characterizations.

\subsubsection{Synthesis of Titania Nanoparticles}

The different phases of titania were synthesized by wet chemical method using TTIP as titania precursor. $6 \mathrm{ml}$ of TTIP precursor was added to $2 \mathrm{ml}$ of ethanol. The resulting mixture was magnetically stirred at $55^{\circ} \mathrm{C}$. Now, $2 \mathrm{ml}$ of methanol and $60 \mathrm{ml}$ of millipore water was also added dropwise for the completion of chemical reaction. The precipitate obtained was collected, filtered and washed with hot water, ethanol and methanol. The precipitate was dried at $130{ }^{\circ} \mathrm{C} / 12 \mathrm{~h}$ in oven and annealed at 550 and $730{ }^{\circ} \mathrm{C} / 10 \mathrm{~h}$ in a muffle furnace to get two different phases of $\mathrm{TiO}_{2}$. The produced white product was characterized by various characterization techniques.

\subsubsection{Synthesis of Titania_silica Nanoparticles}

$0.5 \mathrm{~g}$ of obtained $\mathrm{TiO}_{2}$ nanoparticles were dispersed in $15 \mathrm{ml}$ of ethanol followed by magnetic stirring, say solution A. On the other hand, same amount of PVA was dispersed in $15 \mathrm{ml}$ of water at $70{ }^{\circ} \mathrm{C}$, say solution B. Now solution B was added to solution A dropwise. It was then dried at $70{ }^{\circ} \mathrm{C} / 2 \mathrm{~h}$ in oven. The purpose of coating PVA over nanoparticles before silica coating was that due to the adhesive nature of PVA, it will bind properly over $\mathrm{TiO}_{2}$ nanoparticles. The obtained PVA coated nano-sized $\mathrm{TiO}_{2}(1 \mathrm{~g})$ were dispersed in $5 \mathrm{ml}$ ethanol and $1.5 \mathrm{ml}$ ammonia solution. Then the solution was magnetically stirred followed by the dropwise addition of $6 \mathrm{ml}$ TEOS. The obtained product was naturally dried and then utilized for various characterizations.

\subsubsection{Synthesis of Titania_polyphenol Nanoparticles}

During the preparation of bare phases of titania nanoparticles, $5 \mathrm{ml}$ of green tea extract was added before the precipitate formation. All the conditions were kept same. 


\subsection{Materials Characterization}

The information about crystallinity and purity of the samples were procured by X-ray diffraction (XRD) pattern using a Rigaku bench top X-ray diffractometer equipped with a monochromatic $\mathrm{Cu}-\mathrm{K} \alpha$ radiation $(\lambda=1.541 \AA)$ as X-ray source and scanning in $2 \theta$ range from 10 to $80^{\circ}$. All FTIR spectra were recorded with a single beam Perkin Elmer instrument (Spectrum BX-500) FTIR Model spectrophotometer. The morphology and the size of powder particles were analyzed by a Scanning Electron Microscope (Zeiss EVO MA-10 SEM operating at 10 $\mathrm{keV}$ ) equipped with an energy dispersive spectrometer (EDS; OXFORD INCA ENERGY 250). The TEM was performed using a FEI Tecnai G2 F30 STWIN operating at $300 \mathrm{kV}$ and a JEOL 2100F operating at $200 \mathrm{kV}$. The UV-Vis absorption spectra of the products were recorded using a UV-Vis spectrometer (UV-2401 PC, Shimadzu Corporation Japan). The room temperature Photoluminescence (PL) spectroscopy was done on FL1039 HORIBA JOBIN YVON, USA.

\subsection{Photocatalysis Reaction}

The photocatalytic degradation of MO (Methyl Orange) was examined using the different phases of $\mathrm{TiO}_{2}$ as photocatalyst at various time intervals. The bare and core_shell nanoparticles of anatase and rutile were used as photocatalyst. A $0.01 \mathrm{~g}$ of the photocatalyst was suspended in a $50 \mathrm{ml} \mathrm{MO}$ aqueous solution with an initial concentration of $0.153 \mathrm{mg} \mathrm{l}^{-1}$ in a sealed beaker. Prior to irradiation, the solution was magnetically stirred for an hour at ambient temperature in dark to establish the adsorption-desorption equilibrium. The optical system for the photocatalytic reaction was composed of $150 \mathrm{~W}$ lamp. One millilitre of the solution was drawn out and concentration of $\mathrm{MO}$ at $0,30,60$ and 120 min was calculated using absorption graph obtained from UV-Vis spectrophotometer. The distance between UV light and the sample was $20 \mathrm{~cm}$ that was kept constant throughout. The ability and comparison of photodegradation of MO solution by bare-, silica coated- and polyphenol coated- $\mathrm{TiO}_{2}$ nanoparticles were scrutinized.

\section{Results and Discussion}

\subsection{Crystallographic Phase Transition and Phase Identification}

The phase and phase purity of $\mathrm{TiO}_{2}$ particles prepared at various annealing temperatures of 550 and $730{ }^{\circ} \mathrm{C}$ were determined by XRD as shown in figure 1 . X-ray diffraction patterns of the sample annealed at $550{ }^{\circ} \mathrm{C}$, figure 1(a1), (a2) and (a3), can be indexed to the tetragonal anatase structure (JCPDF-ICDD card no.- 
84-1286). The intensity of the diffraction peaks of anatase_silica and anatase_polyphenol are much

lower than those for the bare anatase, but in all three cases the peaks are located at $2 \theta=25.60,37.9$, $48.28,54.24,55.18,62.86,69,70.48,75.2$. The peak centred at 25.60 with FWHM (Full width at half maximum, obtained by gauss fit) 0.36 was used to obtain the crystallite size of anatase by DebyeScherrer equation. The obtained crystallite size was $23 \mathrm{~nm}$. An interesting finding scrutinized that the crystallite size was found to be decreased when anatase was coated with silica [40] and polyphenol and also hints the existence of core_shell nanostructures. The crystallite size of anatase_silica and anatase_polyphenol was calculated as 19.1 and $17.8 \mathrm{~nm}$, respectively. The peaks in case of anatase_polyphenol were found to be sharper which may be attributed to its high crystallinity. The diffraction peaks of the sample annealed at $730{ }^{\circ} \mathrm{C}$, figure $1(\mathrm{~b} 1)$, (b2) and (b3), were found to be correlated with the documented tetragonal rutile phase (JCPDF-ICDD card no.- 88-1172), the peak

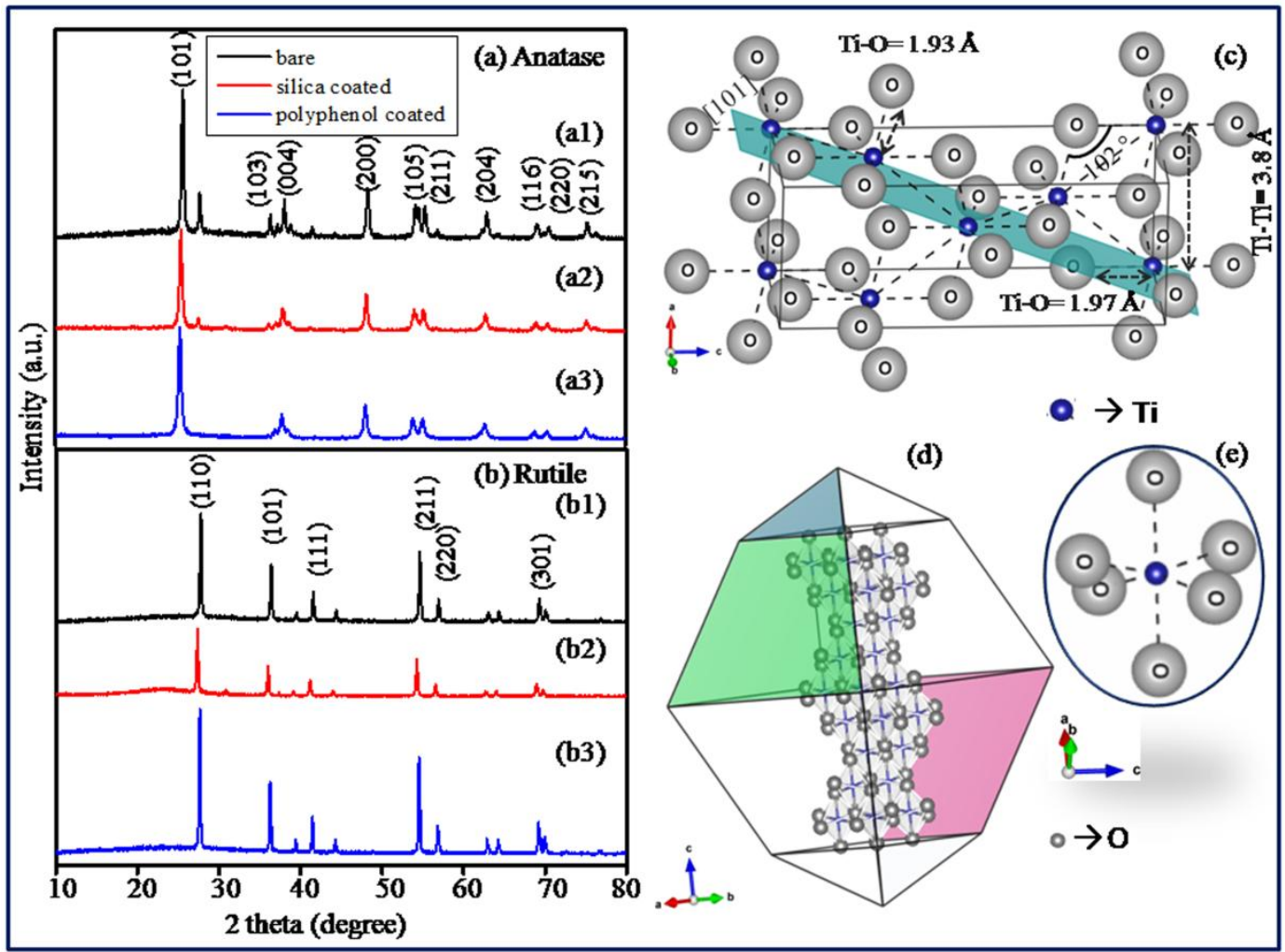

Figure 1. XRD pattern of (a) anatase and (b) rutile phases of $\mathrm{TiO}_{2}$, where $(a 1, b 1),(a 2, b 2)$ and (a3, b3) represent corresponding bare-, silica coated-, and polyphenol coated- $\mathrm{TiO}_{2}$, respectively. (c) crystallographic ball-and-stick model and (d) crystal shape of tetragonal anatase; color code: blue (small) balls indicate titanium (Ti) atoms and grey (large) balls signify oxygen $(O)$ atoms, green square represents [101] plane, blue, green and pink illustrate ( $0-1$ - 3 $),\left(\begin{array}{lll}0 & -1 & 1\end{array}\right)$ and (-1 $\left.0-1\right)$ face, respectively, (e) provides the repeating unit of anatase.

\section{5 column image, $500 \mathrm{dpi}$, image width $140 \mathrm{~mm}$}


centred at 27.8 with FWHM (obtained by gauss fit) 0.23 calculates the crystallite size to be $36 \mathrm{~nm}$ by keeping the position same. The crystallite size was obtained to be $35.7 \mathrm{~nm}$. The peaks observed for rutile_polyphenol were sharp and an increase in crystallite size, $48.2 \mathrm{~nm}$, was observed proving its more crystalline nature. Even, the diffraction peaks of rutile_polyphenol were narrower than its corresponding anatase phase also. No extra peaks were observed apart from the two phases of $\mathrm{TiO}_{2}$ showing the absence of any remnant and also it is because of low content of silica, polyphenol and amorphous phase of silica [41]. The crystallographic ball-and-stick model of tetragonal anatase, figure 1(c), represents the two kind of bonding of titanium with oxygen atom. The axial Ti-O bond length was found to be $1.97 \AA$ and the equatorial Ti-O bond length was calculated as $1.93 \AA$. Axial bond length was found to be longer and thus weaker than the equatorial $\mathrm{Ti}-\mathrm{O}$ bond length. The angle $\mathrm{Ti}-\mathrm{O}-\mathrm{Ti}$ was observed as $102^{\circ}$. The various faces of the crystal shape of anatase have been shown in figure $1(\mathrm{~d})$. The repeating unit of $\mathrm{TiO}_{2}$ is octahedral in nature where the two axial and four equatorial Ti-O bonds are easily distinguishable as depicted in figure $1(\mathrm{e})$.

\subsection{FTIR Spectroscopy}

FTIR spectroscopy was performed to further investigate the nature of chemical bonding present in bareand coated- $\mathrm{TiO}_{2}$ nanoparticles. The bands in the region $800-400 \mathrm{~cm}^{-1}$ correspond to Ti-O and Ti-O-Ti bonds as shown in figure 2 . Thus the peaks at $745,488,770,463,790$ and $513 \mathrm{~cm}^{-1}$ can be associated with $v(\mathrm{Ti}-\mathrm{O})$ vibration. Bands at 1431, 1451, 1444, 1648, 1655 and $1641 \mathrm{~cm}^{-1}$ can be attributed to O-H bending mode. Also, broad band in the region $3650-3000 \mathrm{~cm}^{-1}$ can be assigned for physically adsorbed water [42-44]. In case of silica coated phases of $\mathrm{TiO}_{2}$, the amorphous silica absorbs in $1200-1000 \mathrm{~cm}^{-1}$ as shown in the figure 2(a2), (b2). So, the peak at $1076 \mathrm{~cm}^{-1}$ corresponds to $v(\mathrm{Si}-\mathrm{O}-\mathrm{Si})$ and the two peaks at 1096 and $1180 \mathrm{~cm}^{-1}$ are associated with Si-O-Ti bond [45-46]. The peak at $953 \mathrm{~cm}^{-1}$ corresponds to Si-OH peak and the carbonyl group peak can be assigned at $1716 \mathrm{~cm}^{-1}$. The peak at $2384 \mathrm{~cm}^{-1}$ substantiates to the absorption of atmospheric $\mathrm{CO}_{2}$ [47-48]. Rutile provides evidence of some extra peaks at around 1028 and $1165 \mathrm{~cm}^{-1}$ that can be substantiated to carbonate ions and their presence can be due to the dissolution of $\mathrm{CO}_{2}$ from air [49-50]. The two bands at 2514 and $2922 \mathrm{~cm}^{-1}$ represent the combination bands [51]. After that the pure phases of titania products are compared with their corresponding polyphenol coated phases. Interestingly, Ti-O bands were found to be bathochromic (red) shifted from 745 to $488 \mathrm{~cm}^{-1}$ (in case of anatase) and from 


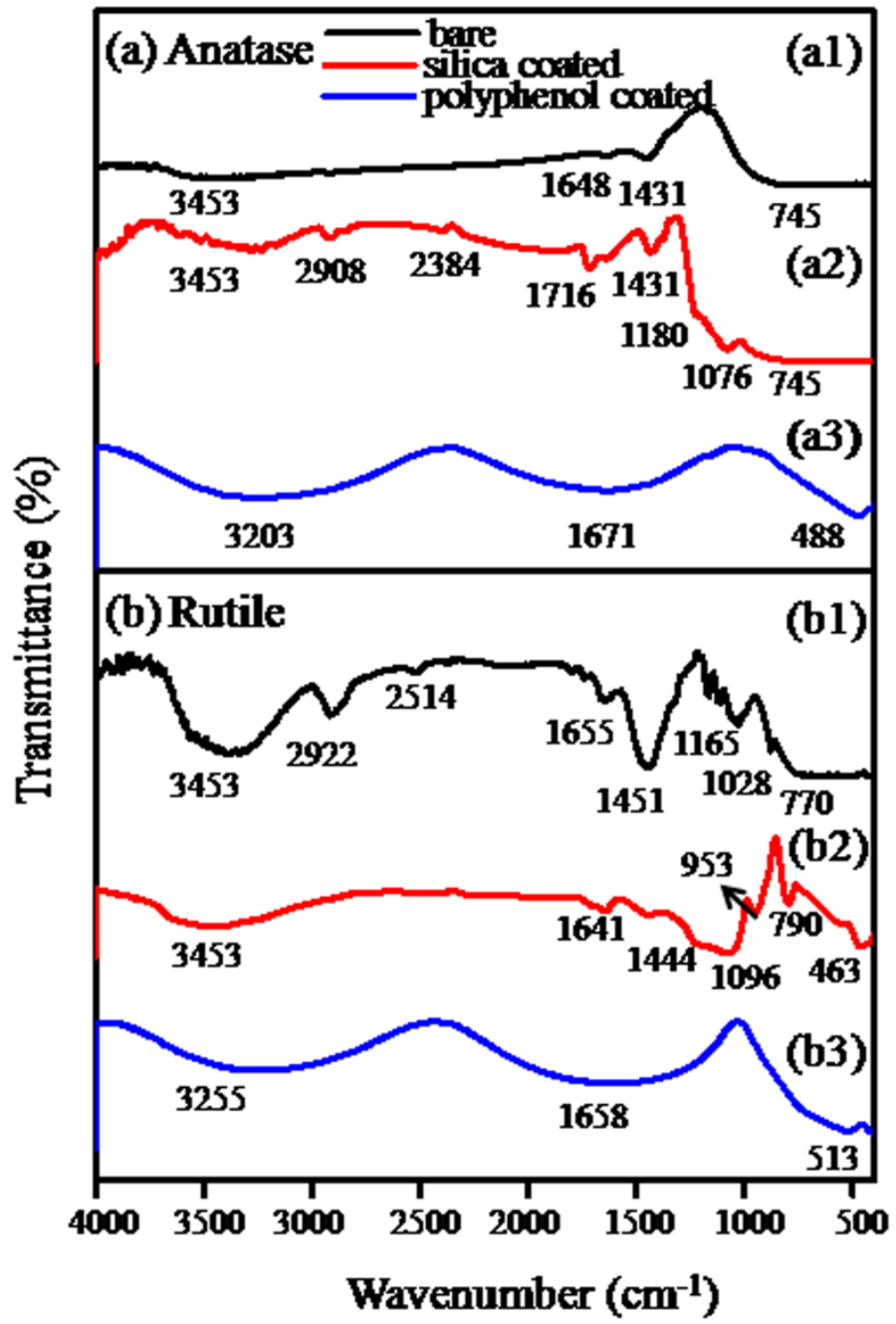

Figure 2. FTIR spectra of (a) anatase and (b) rutile phase of $\mathrm{TiO}_{2}$, where $(a 1, b 1),(a 2, b 2)$ and (a3, b3) represent corresponding bare-, silica coated-, and polyphenol coated- $\mathrm{TiO}_{2}$, respectively.

Single column image, $500 \mathrm{dpi}$, image width $90 \mathrm{~mm}$

770 to $513 \mathrm{~cm}^{-1}$ (in case of rutile) due to the weakening or elongation of Ti-O bond [52]. The peaks shown in figure 2(a3), (b3) are accredited at 1671 and $1658 \mathrm{~cm}^{-1}$ in polyphenol coated phases of titania nanoparticles can be attributed to $\mathrm{C}=\mathrm{C}$ ring stretching in polyphenol $[32,39]$.

\subsection{Topography and Morphological Characteristics}

The morphology and microstructures were characterized by SEM and TEM. The SEM micrographs of bare- and coated- $\mathrm{TiO}_{2}$ project the morphological evolution as shown in figure 3. The micrographs reveal the size of the nanoparticles and provide information about their agglomeration. It was found that the particle size decreases and agglomeration increases in bare forms of $\mathrm{TiO}_{2}$ with the increase in annealing temperature from 550 to $730{ }^{\circ} \mathrm{C}$ as shown in figure $3(\mathrm{a} 1, \mathrm{~b} 1)$. As $\mathrm{TiO}_{2}$ nanoparticles are 
found to agglomerate strongly, thus zeta-potential measurement can help in stability study [53]. The increase in particle size due to coating with silica is evident in figure $3(\mathrm{a} 2, \mathrm{~b} 2)$. In the case of polyphenol coating, the monodispersity of nanoparticles is noticeable as revealed by figure 3(a3, b3). The anatase_polyphenol represents refined and highly compact structure wherein no open surfaces are found. In contrast, the rutile_polyphenol microstructures provide evidence of porosity. To unravel the elemental composition, energy dispersive X-ray spectroscopy (EDS) was conducted that reveal the presence of $\mathrm{Si}$ in the silica coated samples as shown in figure 3(c2), with little evidence of carbon as depicted in figure 3(c3), along with $\mathrm{Ti}$ and $\mathrm{O}$ atoms in polyphenol coated products.

High-resolution TEM was performed to evaluate coating uniformity and coating roughness [54], as illustrated in figure 4. A typical bright field TEM image at high magnification shows the bare anatase nanoparticles with sizes ranging from 40-100 $\mathrm{nm}$. The crystal structure analysis of titania nanoparticles are confirmed based on lattice fringe image as displayed in the inset of figure 4(a). The TEM images show well organised lattice fringes of

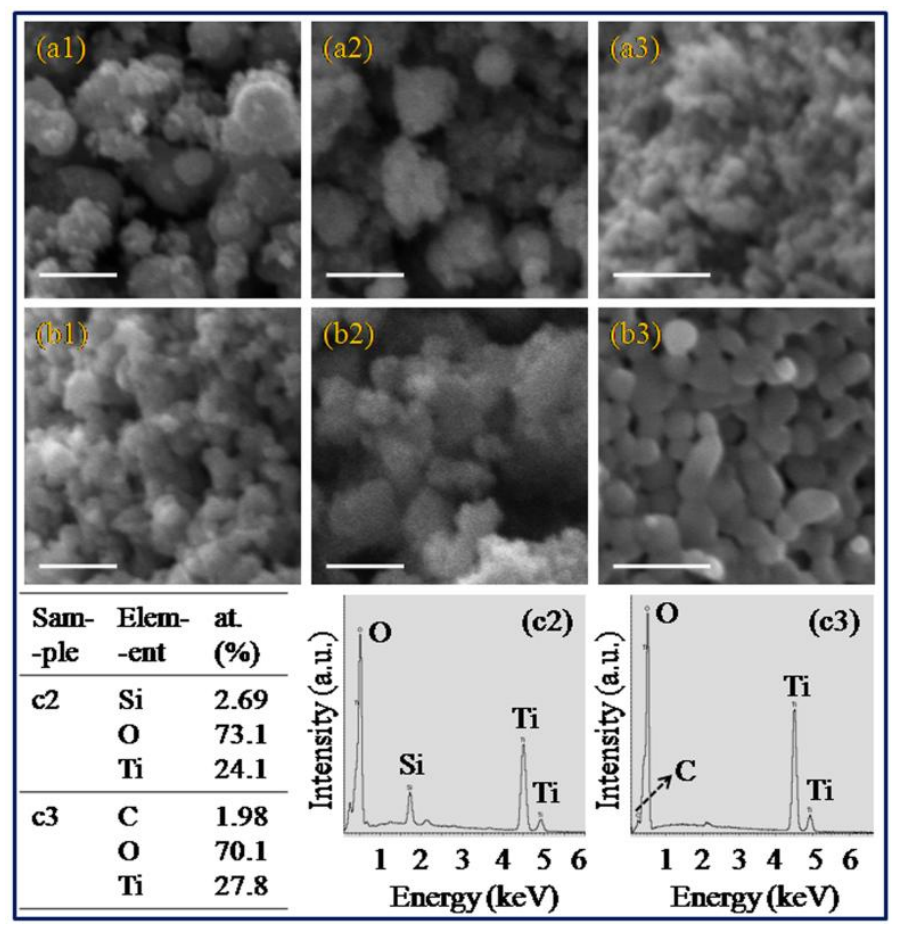

Figure 3. SEM micrographs of anatase and rutile phase of $\mathrm{TiO}_{2}$ where, $(a 1, b 1),(a 2, b 2)$ and (a3, b3) represent corresponding bare-, silica coated-, and polyphenol coated- $\mathrm{TiO}_{2}$, respectively. EDS spectra of corresponding (c2) silica coated-and (c3) polyphenol coated-rutile phase of $\mathrm{TiO}_{2}$. Scale bar=1 $\mu \mathrm{m}$.

\section{Single column image, $500 \mathrm{dpi}$, image width $90 \mathrm{~mm}$}

spacing $\mathrm{d}=0.34 \mathrm{~nm}$ that represents the $\mathrm{d}$ - spacing between (101) planes of $\mathrm{TiO}_{2}$, anatase phase. The stacking of (101) is atomically clean without any imperfections at the lattice scale within the grain. Figure 4(b) shows a 
bright field image of anatase nanoparticle clusters coated with silica. The diameters of two anatase clusters visible in Figures $4 \mathrm{~b}$ and $4 \mathrm{c}$ are about 800 and $350 \mathrm{~nm}$. The lattice fringe d-spacing of $0.34 \mathrm{~nm}$ is consistent with the (101) plane of anatase phase, inset of figure 4(b), further confirming the nature of $\mathrm{TiO}_{2}$ particles. In high resolution HAADF-STEM (Z-contrast) images the anatase nanoclusters appear dark and silica coating appears bright as shown in figure 4(c). EDS mapping in figure 4(d) also substantiates the formation of core_shell

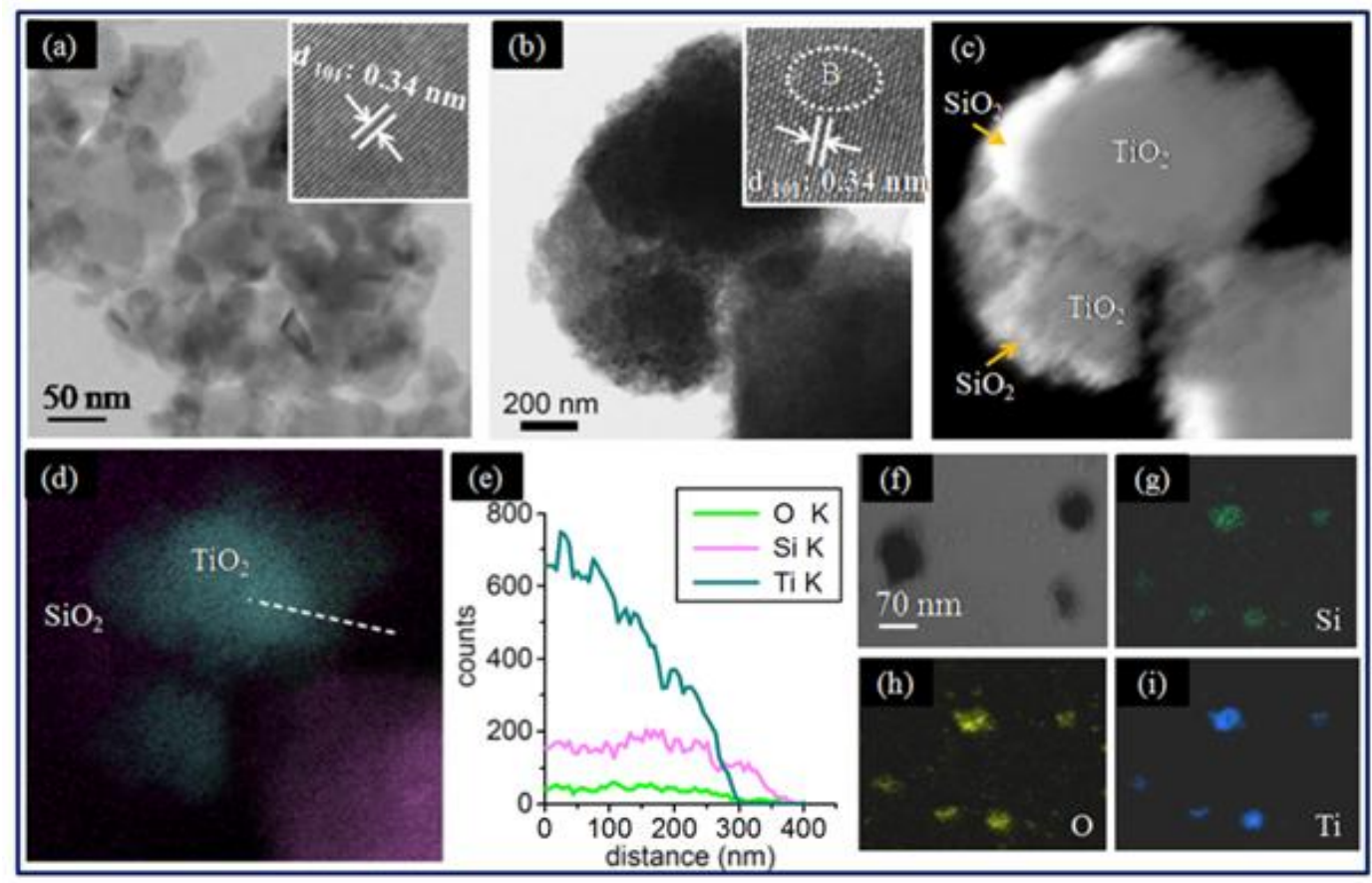

Figure 4. TEM images of bare and silica coated anatase. (a) low magnification micrograph of anatase, (b) Bright field image of two NPs showing core_shell-like structure in case of anatase_silica, (c) corresponding HAADF-STEM image of anatase_silica, (d) EDS mapping supporting core_shell structure of anatase_silica, (e) EDS line scan indicates core_shell structure (80 $\mathrm{nm}$ extra silica), (f) Image of anatase_silica, and ( $g$-i) corresponding EDS elemental mapping images of $(g)$ Si element $(h) O$ element $(i)$ Ti element. Insets in $(a)$ and (b) represent HR-TEM images showing the lattice spacing. White dotted circle $B$ in $(b)$ reveals the overlapped grain boundaries.

\section{5 column image, $500 \mathrm{dpi}$, image width $140 \mathrm{~mm}$}

structure. The thickness of the silica shell on this particle as determined by an EDS line scan was found to be 80 $\mathrm{nm}$ as shown in figure 4(e). The average coating thickness statistically measured from 10 different particles was found to be $100 \mathrm{~nm}$. The EDS elemental mapping also indicates uniform coating as shown in figure 4(f) and the presence of $\mathrm{Si}, \mathrm{O}$, Ti elements as revealed in figure 4(g-i). The rutile nanoparticle clusters are typically 150-200 $\mathrm{nm}$ in diameter, and the silica coating thickness was found to be $20 \mathrm{~nm}$ as shown in bright field image, figure 5(a). The silica coating on rutile nanoparticle clusters is typically more uniform and the interface between core and shell is more distinct than for the case of anatase particles (figure 5a). This is likely due to the more 


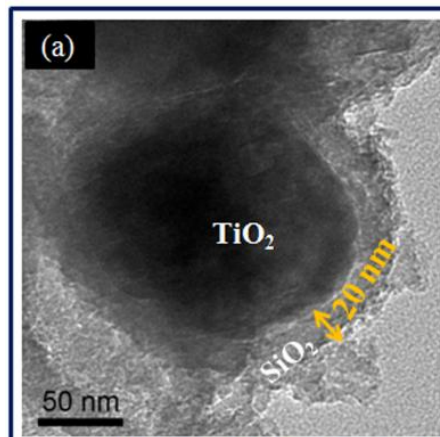

\section{(b)}
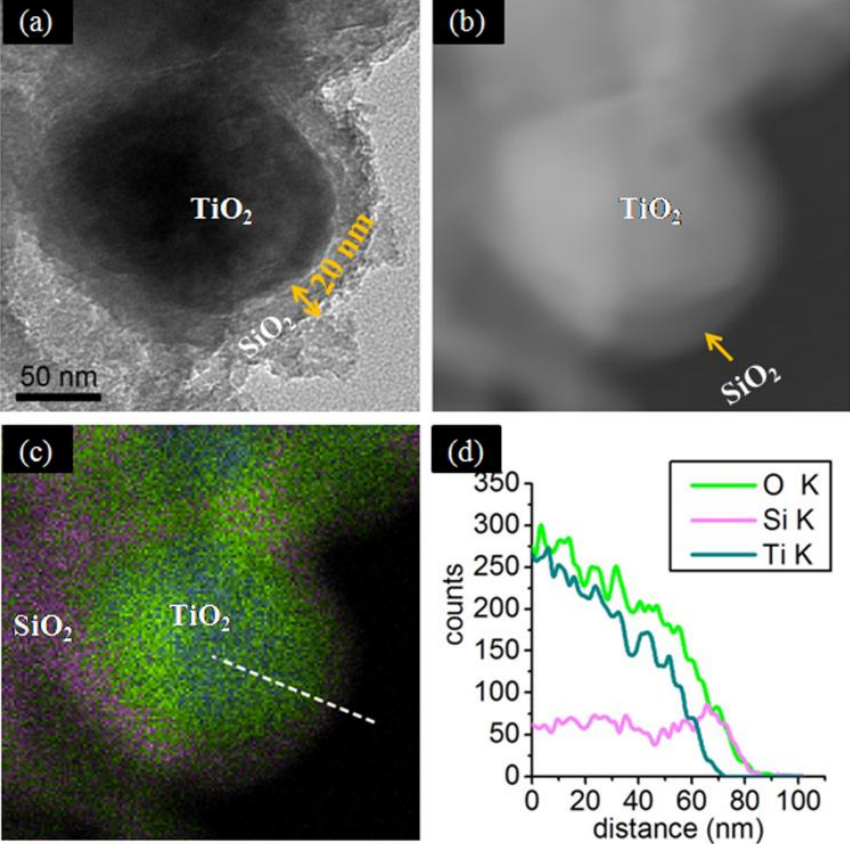

Figure 5. Images revealing core_shell structure of rutile_silica nanoparticles. (a) Bright field image of a nanoparticle cluster showing silica thickness $20 \mathrm{~nm}$., (b) corresponding HAADF-STEM image, (c) EDS mapping, (d) EDS line scan reflecting the shell structure, revealing $20 \mathrm{~nm}$ extra silica. 


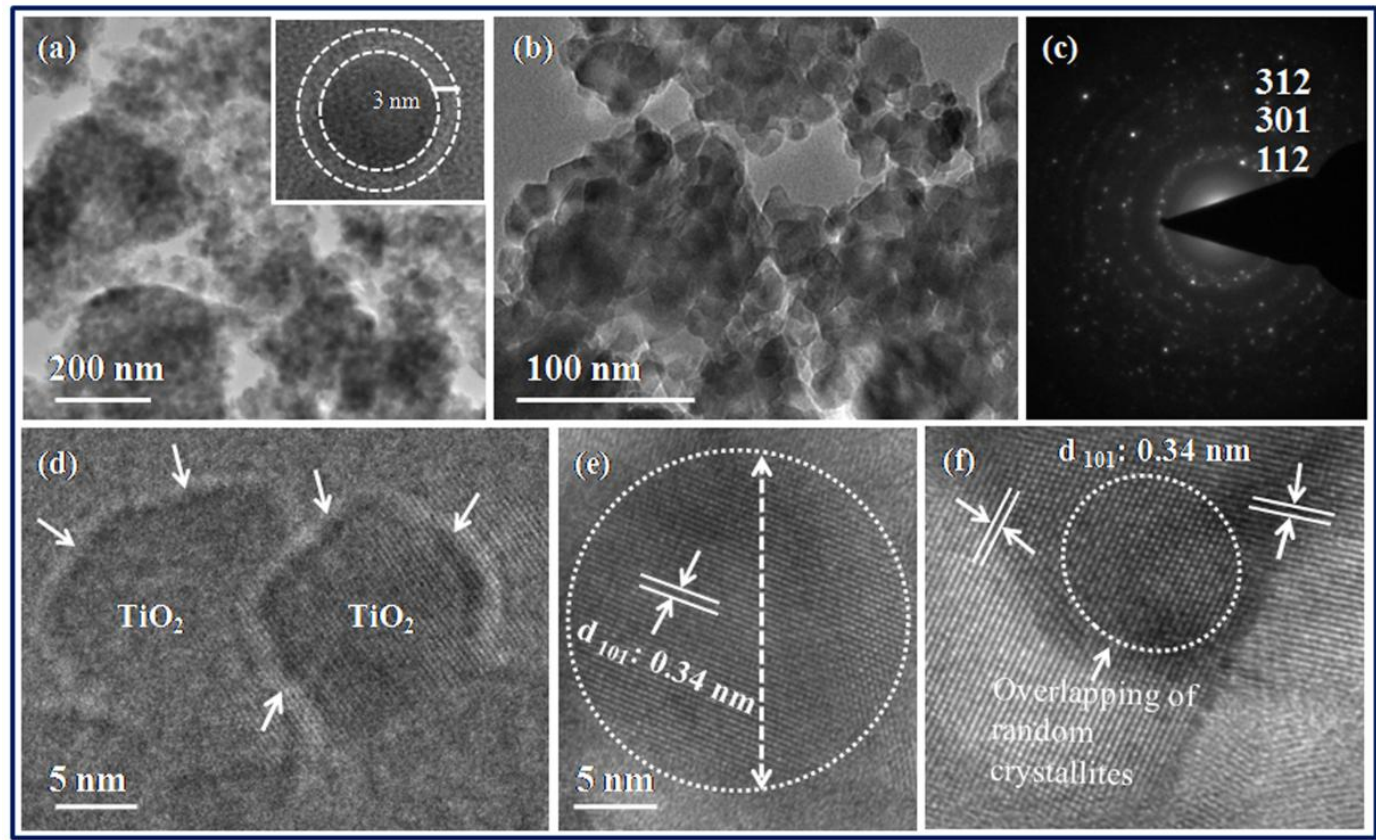

Figure 6. TEM images of polyphenol coated anatase phase. (a), (b) represent the low magnification images, (c) SAED pattern, $(d),(e)$, and (f) illustrate HRTEM images showing lattice fringes. Inset in $(a)$ reveal the thickness of coating. White dotted circle in $(e)$, $(f)$ illustrate the size of a particle and the multiple grain boundary formation due to overlapping of crystallites, respectively. White arrows in (d) elucidate the polyphenol coating.

\section{5 column image, $500 \mathrm{dpi}$, image width $140 \mathrm{~mm}$}

\subsection{Mechanism of the interaction of Silica and polyphenol with $\mathrm{TiO}_{2}$ phases}

\subsubsection{Silica interaction with $\mathrm{TiO}_{2}$ Nanoparticles}

There can be two ways of the interaction of silica with $\mathrm{TiO}_{2}$ phases, either $\mathrm{Si}$ can interact with $\mathrm{TiO}_{2}$ at its

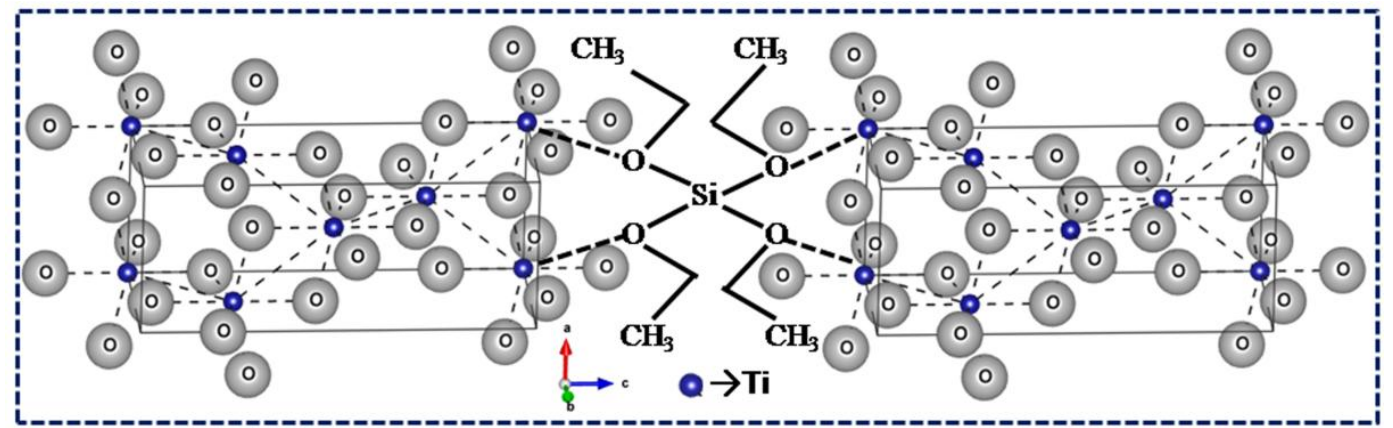

Scheme 1. Schematic representation of the mechanism of Si interacted at the surface of anatase nanoparticles.

\section{5 column image, $500 \mathrm{dpi}$, image width $140 \mathrm{~mm}$}

surface or it can get incorporated into the crystal structure of $\mathrm{TiO}_{2}$ as shown in Scheme 1. There occurs the formation of Ti-O-Si bond at the surface of titania nanocrystals as confirmed by FTIR spectroscopy. If Si gets 
incorporated into the crystal structure of $\mathrm{TiO}_{2}$, then there can be two mechanisms; (i) One of them consist of the incorporation of $\mathrm{Si}$ into the $\mathrm{TiO}_{2}$ crystal interstitially, (ii) The second possibility may be Si incorporation into the crystal structure of $\mathrm{TiO}_{2}$ substitutionally and thereby altering the lattice parameters. $\mathrm{Ti}^{4+}$ has an ionic radius of $0.68 \AA$ while the ionic radius of $\mathrm{Si}^{4+}$ is $0.42 \AA$. Thus it is very small enough to enter into the interstices of $\mathrm{TiO}_{2}$ crystal [56]. There are two vacant interstitial sites in which the extra cation could be accommodated in the rutile structure: $\left(\begin{array}{lll}0 & 0.5 & 0\end{array}\right)$ octahedral positions and $\left(\begin{array}{lll}0 & 0.5 & 0.25\end{array}\right)$ tetrahedral sites [57]. The incorporation of $\mathrm{Si}$ atom in octahedral positions is represented in Scheme 2(b), where the inset clearly reveals the coordination state of Ti-atom. The incorporated Si atoms in tetrahedral position of rutile are ascribed in the Scheme 2(c). When $\mathrm{Si}^{4+}$ replaces $\mathrm{Ti}^{4+}$ into the anatase crystal structure substitutionally and randomly, the lattice parameters and unit cell volume decrease slightly. The parameter $a$ decreases only slightly from 0.3782 to $0.3781 \mathrm{~nm}$, and $c$ decreases from 0.952 to $0.9405 \mathrm{~nm}$ [58]. Scheme 2(d) represents the $\mathrm{Si}$ atom incorporation substitutionally at some random places into the anatase crystal.

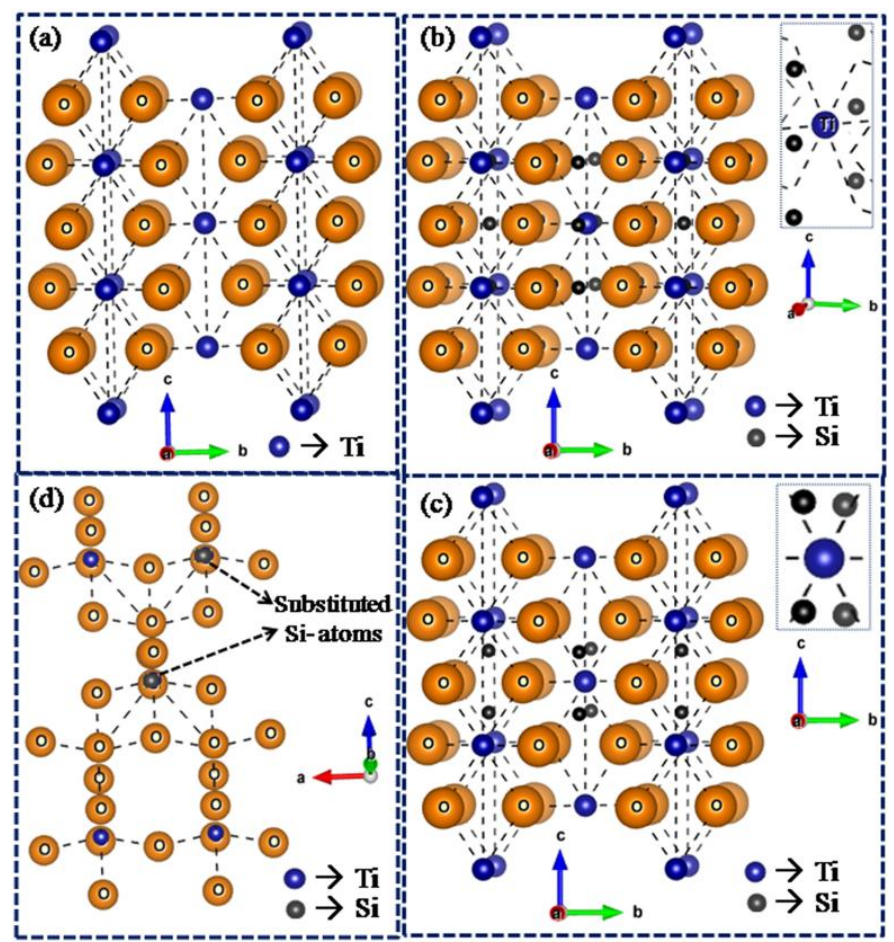

Scheme 2. Pictorial representation of Si incorporation in the crystal structure of titania phases. Ball and stick model of (a) rutile, Si- atom incorporation in (b) octahedral positions, (c) tetrahedral positions of rutile. (d) Substitution of Ti atom by Si atom in some positions of anatase. Insets clearly represent the coordination state of titanium atom when Si is incorporated.

\section{Single column image, $500 \mathrm{dpi}$, image width $90 \mathrm{~mm}$}




\subsubsection{Polyphenol interaction with $\mathrm{TiO}_{2}$ Nanoparticles}

The main constituent of green tea is polyphenols, predominantly the catechins. Out of catechins, EGCG is the main polyphenolic component found which interacts via its hydroxyl group with $\mathrm{TiO}_{2}$ surface [29-31]. It is also evidenced by FTIR data, figure 2(a3, b3), where the peak of metal oxide bond was found to be shifted towards lower wavenumber that points to the weakening of $\mathrm{Ti}-\mathrm{O}$ bond of $\mathrm{TiO}_{2}$ nanostructure. This weakening of bond clearly illustrates that $\mathrm{Ti}-\mathrm{O}$ bond in $\mathrm{TiO}_{2}$ gets elongates/weakens up presumably due to some chemical interaction with hydroxyl groups of the green tea component. EGCG is found to interact with those hydroxyl groups which are less bulky and are present at meta position to each other, as shown in Scheme 3.

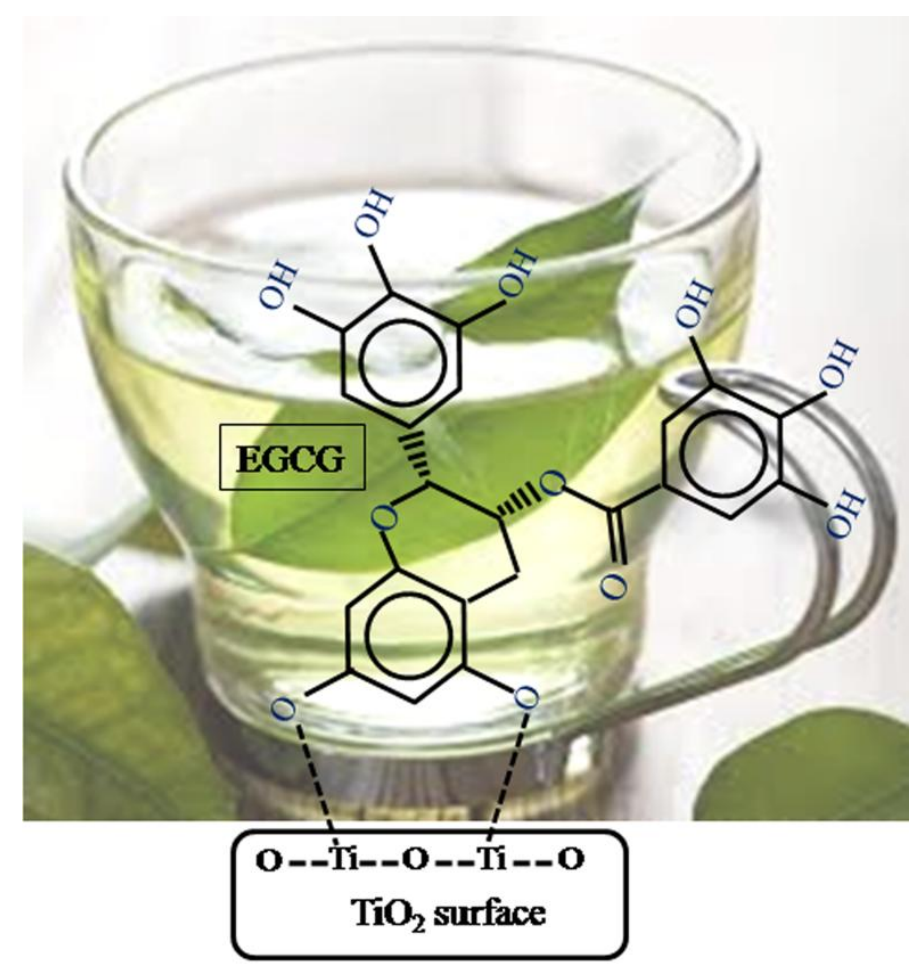

Scheme 3. Pictorial representation of the chemical interaction between EGCG, a polyphenol and $\mathrm{TiO}_{2}$ surface.

\section{Single column image, $500 \mathrm{dpi}$, image width $90 \mathrm{~mm}$}

\subsection{Optical Property Determination}

Figure 7 represent the UV-Vis spectra of coated (with silica and polyphenol) and bare $\mathrm{TiO}_{2}$ phases prepared at the two annealing temperatures. In figure 7(a), all the three forms of anatase i.e. bare, silica coated and polyphenol coated, show an absorbance at $251 \mathrm{~nm}$, whereas in coated forms blue shift is also noticed at $224 \mathrm{~nm}$ 
for silica and at $221 \mathrm{~nm}$ for polyphenol that may be accounted for the variation in the particle size. In case of anatase_polyphenol, the absorbance at $221 \mathrm{~nm}$ depicts higher blue shift as compared to the absorbance at 224 $\mathrm{nm}$ in anatase_silica. Figure 7(b) portrays the UV-Vis absorbance spectra of all the three forms of rutile i.e. bare, silica coated and polyphenol coated. All of three forms show the peak at $256 \mathrm{~nm}$ which is found to be red shifted as compared to corresponding anatase forms, figure 7(a), because of increase in particle size at higher annealing temperature. The silica coated rutile validates absorbance at $287 \mathrm{~nm}$ which is red shifted as compared to bare rutile and polyphenol coated show the absorbance at $221 \mathrm{~nm}$ which is blue shifted. Obviously, the red shifted peak is because of increase in the size of rutile_silica. The similar peak at $251 \mathrm{~nm}$ in case of both bare and coated forms of anatase and at $256 \mathrm{~nm}$ in bare and coated rutile form clearly indicate no change in optical property which is found to be in agreement with the result obtained by Gass et.al. [17].

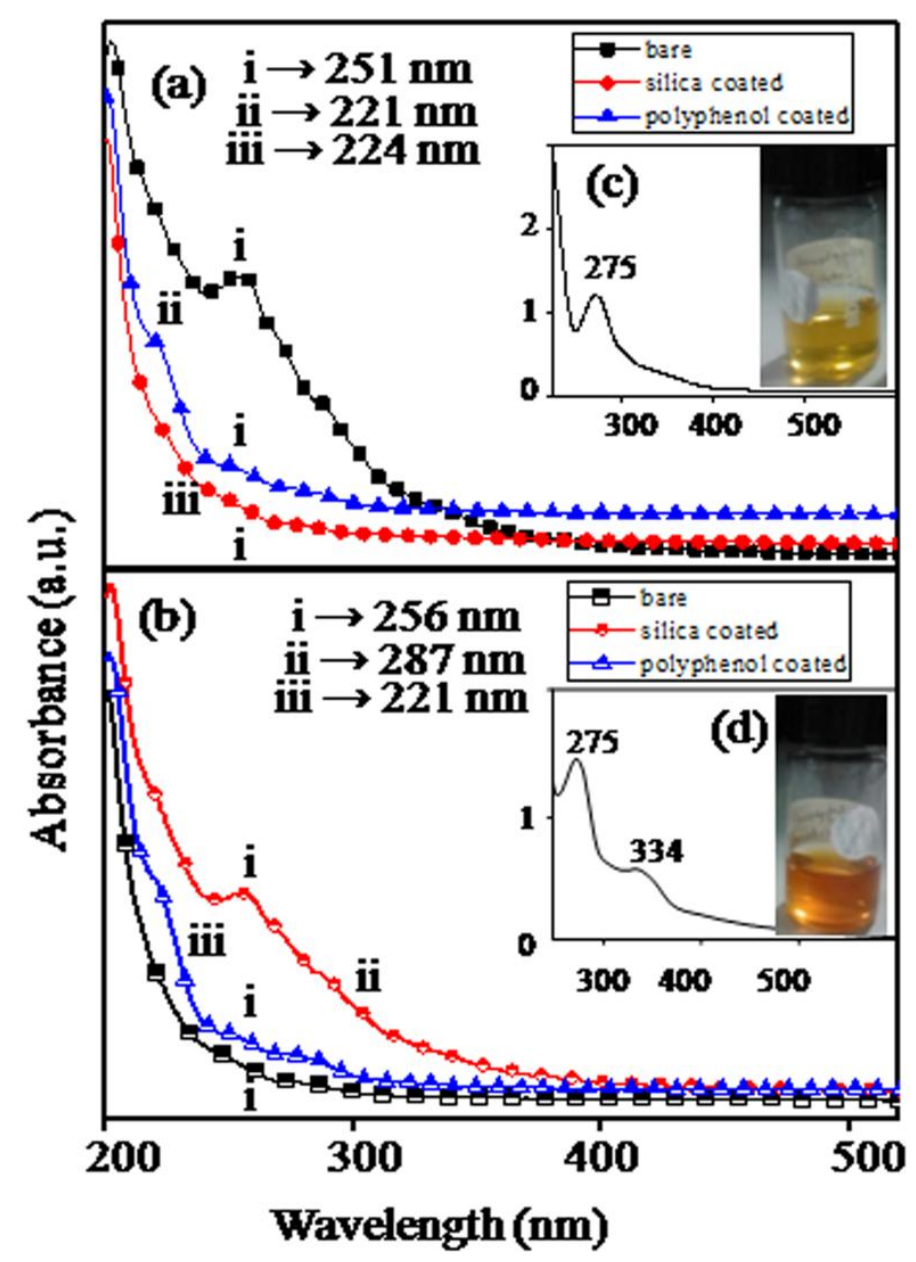

Figure 7. UV-Vis spectra of (a) anatase phase, (b) rutile phase, (c) fresh polyphenol solution, (d) oxidised polyphenol solution. 
Absorbance peak at $275 \mathrm{~nm}$ as shown in figure 7(c) may correspond to $\pi \rightarrow \pi^{*}$ transition in case of freshly undergoes oxidation. The reddish colour of this oxidised solution contributes to the formation of thearubigin, figure $7(\mathrm{~d})$.

\subsection{Photo-catalytic and-luminescence study of Anatase}

\subsubsection{Bare Anatase}

The photocatalytic activity of anatase nanoparticles was assessed by analyzing the photo-degradation of MO solution \& then confirmed by PL spectra. Figure $8\left(\mathrm{a}_{10}\right)$ illustrates spectrum of MO degradation with anatase phase as photocatalyst under UV light irradiation at various time intervals. The UV-Vis absorption spectrum of MO solution with initial concentration $0.153 \mathrm{mg} \mathrm{l}^{-1}$, shows a broad band at $464 \mathrm{~nm}$ which corresponds to $\pi \rightarrow \pi^{*}$ transition [59]. In PL spectrum, the three peaks are observed at 334, 394 and 524 $\mathrm{nm}$ in case of bare MO solution as represented in the inset of figure $8\left(\mathrm{a}_{21}\right)$. Upon UV exposure for $30 \mathrm{~min}$, electrons and holes get separated out and are available at the surface of catalyst to carry out degradation. At this time interval, PL emission spectrum shows no sharp peak supporting complete photodegradation and negligible exciton recombination as illustrated in Fig. $8\left(\mathrm{a}_{11}\right)$. As we know that when a photocatalyst is illuminated by UV light with energy equal to or greater than the band gap energy, the valence band (VB) electrons can be excited to conduction band (CB), leaving positive holes into the VB and electrons to the $\mathrm{CB}$ which then helps to degrade the methyl orange dye solution and thus the negligible number of excitons are undergoing recombination resulting in the minimum PL intensity. At 60 min of UV irradiation, the characteristic absorption peak intensity decreases. This decrease was not accompanied by the existence of new peaks or any shift in the spectral location of peaks. The PL emission also shows peak however with moderate intensity indicating that phenomenon, PL and photodegradation, occur simultaneously. Here, excitons are separated out resulting in photodegradation, at the same time exciton recombination also occurs. But the trend seems peculiar after 60 min or second exposure. The photocatalytic activity, instead of increasing, deteriorates at $120 \mathrm{~min}$ that is because of deactivation of catalyst. The catalyst deactivation may occur to some extent due to the formation of number of degraded fragments of $\mathrm{MO}$ at the catalyst surface that block the active site of catalyst and also that solution become concentrated which scatters the UV light instead of transmitting through the solution [60]. It causes hindrance for further photodegradation [61]. So, in this case photodegradation is reduced whereas PL emission shows 


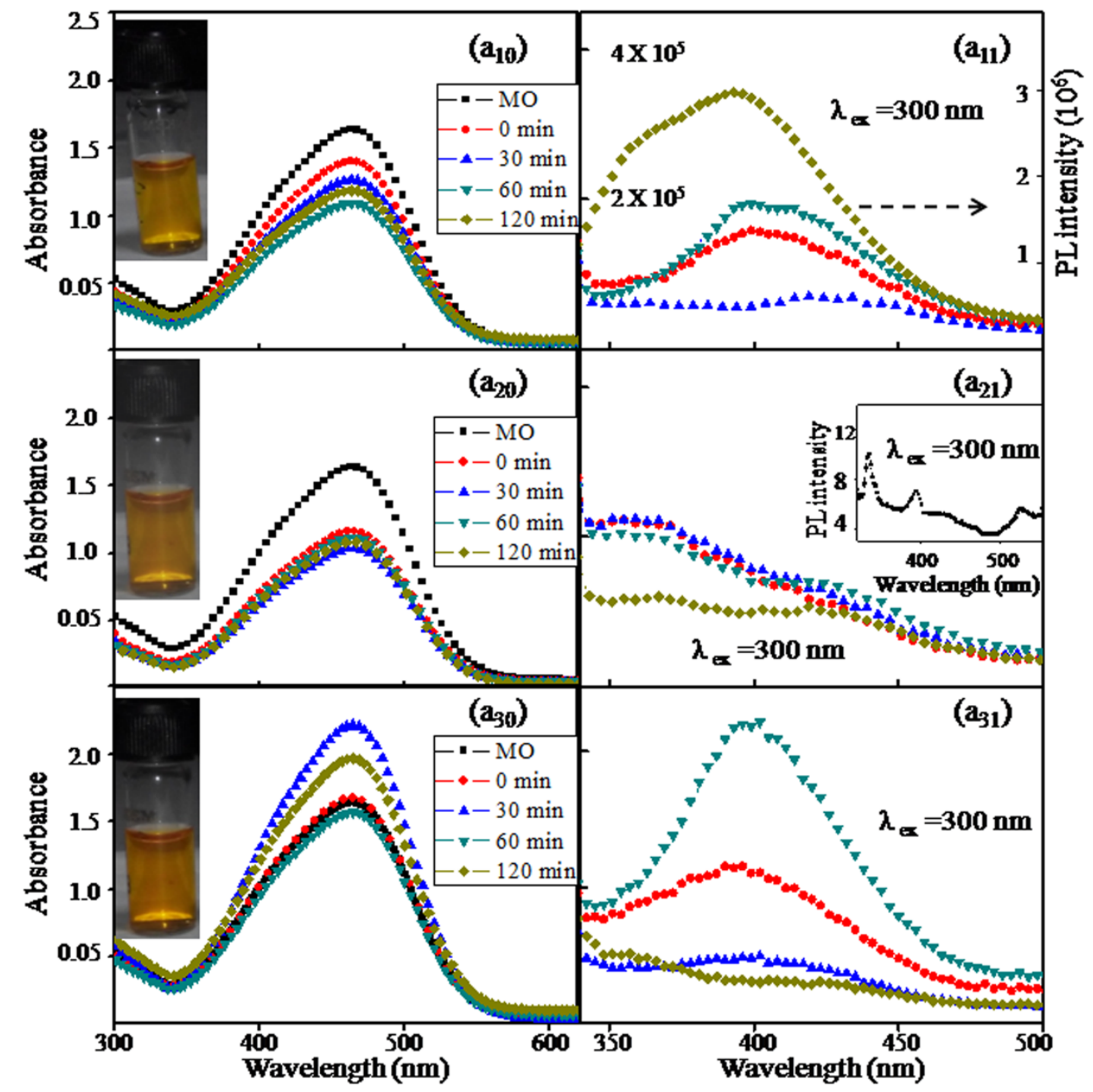

Figure 8. Photo-catalytic and -luminescence spectra of anatase nanoparticles. UV-Vis spectra of photodegradation of methyl orange dye by anatase $\left(a_{10}\right)$, anatase_silica $\left(a_{20}\right)$, anatase_polyphenol $\left(a_{30}\right)$ at various time durations. PL spectra of these samples have also been depicted. $\left(a_{11}\right),\left(a_{21}\right)$ and $\left(a_{31}\right)$ showing the PL characteristics of anatase, anatase_silica and anatase_polyphenol, respectively. Inset in $\left(a_{21}\right)$ represents the PL spectrum of methyl orange at $\lambda_{e x}=300 \mathrm{~nm}$. Y-axes are same in all PL spectra showing PL intensity.

\section{5 column image, $500 \mathrm{dpi}$, image width $140 \mathrm{~mm}$}

highest peak corresponding to the recombination of generated excitons. Also, blue shift was noticed in PL from $404 \mathrm{~nm}$ (at $60 \mathrm{~min})$ to $394 \mathrm{~nm}$ (at $120 \mathrm{~min})$.

\subsubsection{Anatase_silica}

The photocatalytic degradation of MO dye by anatase_silica shows a sharp decrease in absorbance at 0 min as compared to pristine MO solution that may be because of inter/intra chain interactions [62] of the catalyst with MO. As UV exposure is applied, the overlapping absorbance curves can be observed 
with various time irradiations which clearly reveal that the silica coating is uniform which helps to coating not only engulfs all the radicals produced by $\mathrm{TiO}_{2}$ but also prevents its interaction with the surroundings. However, the degree of degradation is found to be less in all the cases as compared to bare anatase due to coating. So, the photocatalytic activity of $\mathrm{TiO}_{2}$ remains almost same with increment in time as shown in the figure $8\left(\mathrm{a}_{20}\right)$. To understand the fate of photogenerated charge carriers, PL spectrum has been employed at excitation wavelength of $300 \mathrm{~nm}$ which illustrated decreasing trend with increasing irradiation time indicating the electrons and holes generated are solely engaged in degradation and not in exciton generation leading to drop in PL emission as shown in figure $8\left(\mathrm{a}_{21}\right)$.

\subsubsection{Anatase_polyphenol}

The photocatalytic degradation of MO dye by anatase_polyphenol represents no change when catalyst is added in the MO solution at 0 min (without UV irradiation) instead it traces the absorbance path of MO solution as represented in Figure 8( $\left.\mathrm{a}_{30}\right)$. After that the trend was found peculiar. The absorbance suddenly increases on 30 min exposure of UV rays corresponds to least photocatalytic activity that is found to be in agreement with highly compact and refined morphology of these nanoparticles (as indicated in figure 3(a3)) which does not allow the photodegradation. However, in case of PL (figure 8( $\left.\mathrm{a}_{31}\right)$ ), the peak position was same but the peak intensity decrease which is not in agreement with the photodegradation result. The reduction in both, PL intensity and photocatalytic activity, can be explained by the repelling/suppression of photoexcited electrons from polyphenol species to anatase domains because of electron donating tendency of polyphenols that results in charge separated state $[32,63]$. At 60 min of UV exposure the absorbance decreases and thus helps in photocatalytic degradation. This shows that prolonged UV irradiation time (around $60 \mathrm{~min}$ ) is required to enhance the photocatalytic activity of anatase_polyphenol due to its compact morphology. However in the PL peak, the peak intensity becomes highest keeping its position same which shows that there is definitely some change in the electronic structure of catalyst [64] which leads to exciton recombination. It is expected that after 60 min of exposure, surplus excitons are generated which due to accumulation supports photocatalysis as well as recombination. Although at 120 min of UV exposure, the absorbance rises and photodegradation diminishes that may be because of non availability of the catalyst surface owing to the degraded fragments of dye. The PL results are in agreement with the photodegradation result that the excitons are utilised to produce radicals instead of getting recombined 
in $120 \mathrm{~min}$ of UV exposure. Here, blue shifting is noticed. In all the cases, it is also noticed that the

absorbance peaks are narrower and even sharper than bare- and silica coated- anatase due to compact morphology leading to surface modification, as evident from the microstructures, figure 3(a3).

\subsection{Photo-catalytic and-luminescence study of Rutile}

\subsubsection{Bare Rutile}

In case of bare rutile, the trend is quite reasonable. Till 30 min exposure of UV-light, the absorbance

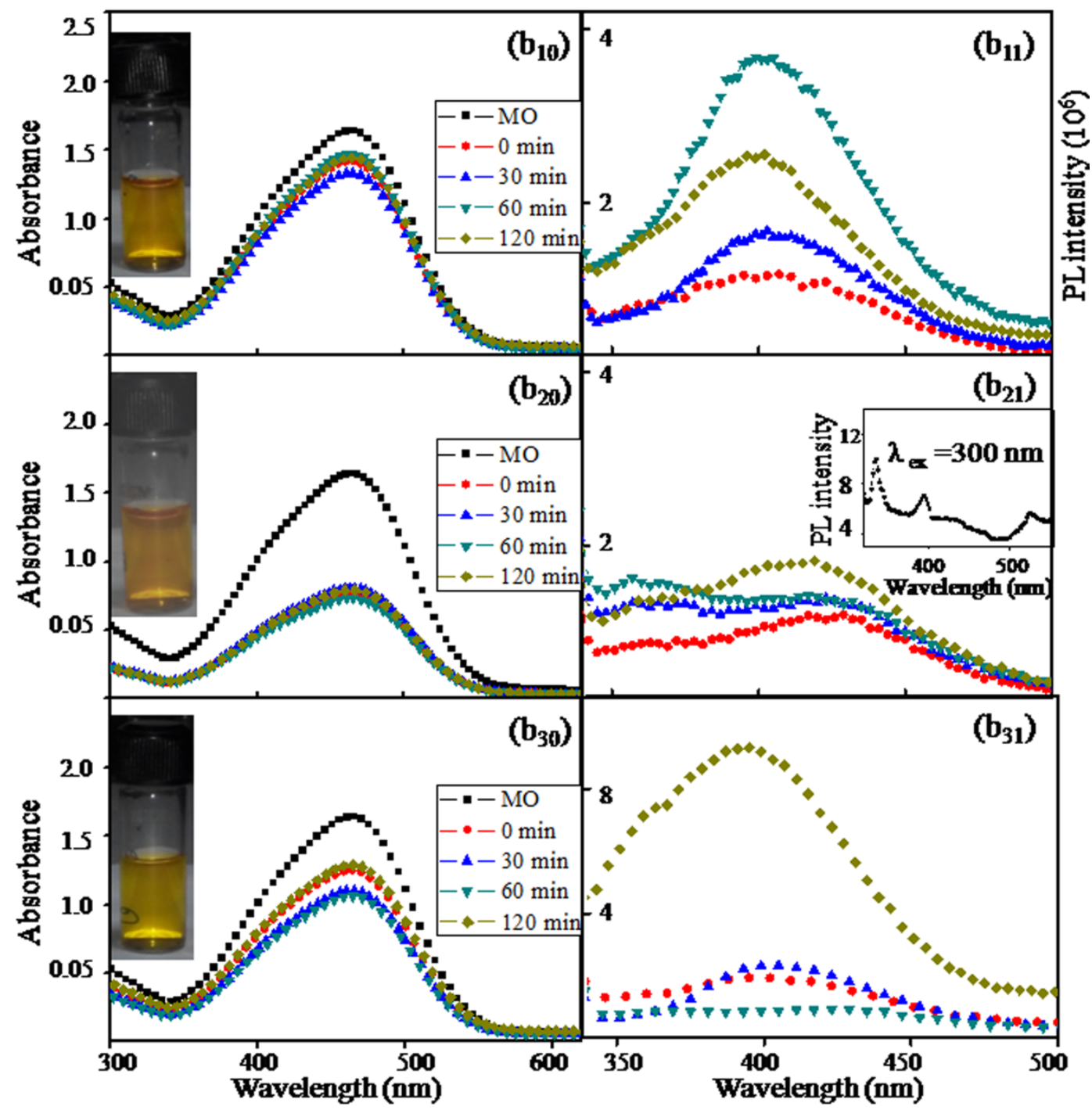

Figure 9. Photo-catalytic and-luminescence spectra of rutile nanoparticles. UV-Vis photocatalytic degradation of $M O$ dye by bare rutile $\left(b_{10}\right)$, rutile_silica $\left(b_{20}\right)$ and rutile_polyphenol $\left(b_{30}\right)$ at various time irradiation. PL spectra at the excitation wavelength of $300 \mathrm{~nm}$ are elucidated in $\left(b_{11}\right),\left(b_{21}\right)$ and $\left(b_{31}\right)$ by bare, silica coated and polyphenol coated rutile, respectively. The inset represented in $\left(b_{21}\right)$ shows the PL spectrum of MO dye.

1.5 column image, 500 dpi, image width $140 \mathrm{~mm}$ 
peak decreases with time, as shown in figure $9\left(b_{10}\right)$ which is quite expected. Whereas the PL emission peaks, as depicted in figure $9\left(b_{11}\right)$, are also found to decrease till $30 \mathrm{~min}$ of UV exposure showing that the photocatalytic activity favours in that interval of time. Whereas, after 30 min the absorbance peak increases that can be explained as with prolonged interval of time the degradation of MO becomes lower leading to the blocked active surfaces of catalyst due to degraded fragments and thus there occurs no significant photocatalytic activity. In this case, the absorbance peaks other than the peak in pristine MO peak, are quite overlapped and quite diminished. However, the absorbance peak decrease very sharply as catalyst is added to the pristine MO solution without UV illumination as represented in figure 9( $\left.b_{20}\right)$. But PL emission peaks show enhanced intensity after 30 min leading to the recombination of excitons generated. The peak intensity varies but the peak positions remain same, at $400 \mathrm{~nm}$. However, the absorbance of pristine MO when catalyst is added under no UV light is found higher in case of bare rutile than its corresponding anatase phase which is obvious as anatase has higher photocatalytic activity than rutile.

\subsubsection{Rutile_silica}

In this case, the absorbance peaks other than the peak in pristine MO peak, are quite overlapped and quite diminished. However, the absorbance peak decrease very sharply as catalyst is added to the pristine MO solution, Fig. $9\left(b_{20}\right)$, without UV illumination. This decrease in the absorbance was found to be more prominent in this case in contrast to the its corresponding anatase phase. Here, it is observed that the PL spectrum peaks indicate the rate of recombination is higher than the rate of photodegradation that is because of coated surface of rutile, figure $9\left(b_{21}\right)$. Our result of reducing the photodegradation of MO dye by coating the rutile form with silica is in correlation with the already reported results in literature [65].

\subsubsection{Rutile_polyphenol}

The increment in photodegradation of MO with increase in UV irradiation till initial period of 60 min is clearly noticed as depicted in figure $9\left(b_{30}\right)$. The absorbance peak decreases after $30 \mathrm{~min}$ of UV irradiation in comparison to $0 \mathrm{~min}$. The PL emission peak can also be noticed during this time interval indicating generation of exciton that supports in $\mathrm{e}^{-}-\mathrm{h}^{+}$separation (photocatalysis) as well as mild recombination. At $60 \mathrm{~min}$ of UV exposure, it seems that exciton generation is reduced (in comparison to exposure at first $30 \mathrm{~min}$ ) leading to less 
photodegradation as well as negligible PL. That may be because of excess fragments owing to the degradation of MO, scattering the exposed UV rays. Further, after prolonged UV irradiation (for 120 min), PL emission favours. The reason is the non availability of the active sites at the catalyst surface and simultaneously the electron donating ability of polyphenol, may suppress the photodegradation thereby enhancing photorecombination similar to anatase_polyphenols. Here, the porous surface morphology represented in figure 3(b3) provides enough active sites for easier photocatalytic reaction. Thus it can be inferred that improved textural properties and efficient electron hole separation are the factors that are responsible for enhanced light photocatalytic activities. Here, the porosity leads to higher surface area that can result in more active and exposed sites for efficient photocatalytic activity.

\subsection{A Comparison on photocatalytic performances of bare and coated-anatase \& -rutile nanostructures}

It can be discussed that in case of bare anatase, UV absorbance decreases at 30 min of UV illumination, which further decreases at $60 \mathrm{~min}$ of prolonged irradiation pointing to the higher photocatalytic activity at $60 \mathrm{~min}$. But after that it exhibits negligible photocatalytic activity. This result is in agreement with PL results which shows highly intensed PL peak at 120 min that corresponds to higher recombination of photogenerated charge carriers, as shown in figure $8\left(\mathrm{a}_{11}\right)$. Although, in case of its silica coated form, the absorbance peak decreases at $30 \mathrm{~min}$ and then increases at $60 \mathrm{~min}$ of UV irradiation which is clearly pointing towards the decrease in photodegradation of an organic dye. That may be due to the thick coating which helps to inhibit the ROS generation and thus photodegradation. This also correlates with PL spectrum that was found to be diminished as compared to its UV absorbance, figure $8\left(\mathrm{a}_{21}\right)$, revealing the fact that silica coating not only prevent the radical generation but it also enhances the UV absorbance. Similarly in case of its corresponding polyphenol coated sample, the UV absorbance suddenly increases at 30 min and then sharply decreases at 60 min of prolonged irradiation. The photocatalytic activity increases at 60 min of time because of some structure modifications as already examined by SEM analysis (Figure 8( $\left.\mathrm{a}_{31}\right)$ ). But that increment is not that sharp. So, in case of $60 \mathrm{~min}$ of illumination, the increase in absorbance in silica coated form is not that significant than the decrease in absorbance peak in case of bare anatase as compared with 0 min of UV irradiation. It clearly reveals that anatase has higher ability to generate ROS as compared to its other coating forms. Comparing the photoactivities of silica and polyphenol coated anatase, polyphenol stabilized form shows higher photocatalytic activity than its silica coated form that may be accounted due to some 
structural/morphological changes and also due to thick coating of silica as compared to ultra-thin coating of polyphenol. To summarize these results, absorbance versus time graph for both the phases of $\mathrm{TiO}_{2}$ nanoparticles have been plotted in figure 10 . Now, the degradation by rutile as photocatalyst was examined. In case of its bare form, the absorbance curve decreases at $30 \mathrm{~min}$ but it rises at $60 \mathrm{~min}$ of UV irradiation which is in agreement with PL results as depicted in Figure $9\left(b_{21}\right)$. In its silica coated form, the UV curve rises which then decreases at $60 \mathrm{~min}$ of the time duration evincing its higher photocatalytic activity but it is not that significant as compared to its corresponding absorbance peak at 0 min of UV light irradiation. Whereas, in its polyphenol stabilized form, the absorbance reduces which again decreases at $60 \mathrm{~min}$ of UV irradiation and thus a significant alter in the absorbance peak magnitude is observed when compared with its corresponding 0 min of light illumination.

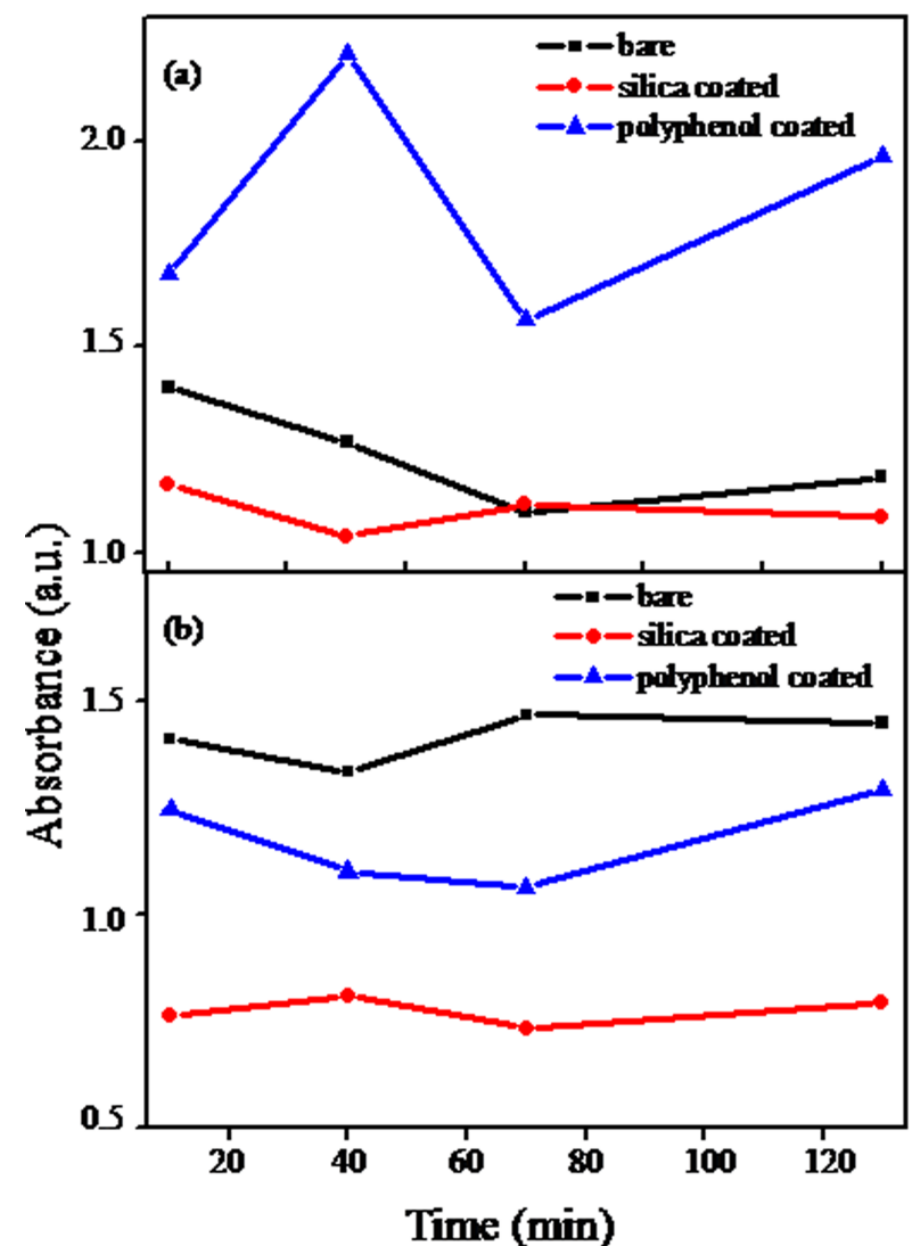

Figure 10. Absorbance versus time graph for $(a)$ anatase and $(b)$ rutile phase of titania nanoparticles. Color code: Black (square) represents bare, red (circle) elucidates -silica coated, and blue (triangle) shows polyphenol coated samples. 
Also, as seen in the microstructure, figure 3(b3), its surface morphology points to its porosity which enhances its photocatalytic activity. To compare the photocatalytic activity of bare and silica coated rutile forms, bare rutile nanoparticles were found to demonstrate higher photodegradation activity because there occurs sharp increase in UV peak as compared to its silica coated form that evince no significant change in its UV absorbance curve when compared the graph at 0 and $60 \mathrm{~min}$ of UV illumination. So, rutile_polyphenol evinces highest photocatalytic activity among the rutile forms.

The obtained results are summarized in Scheme 4.

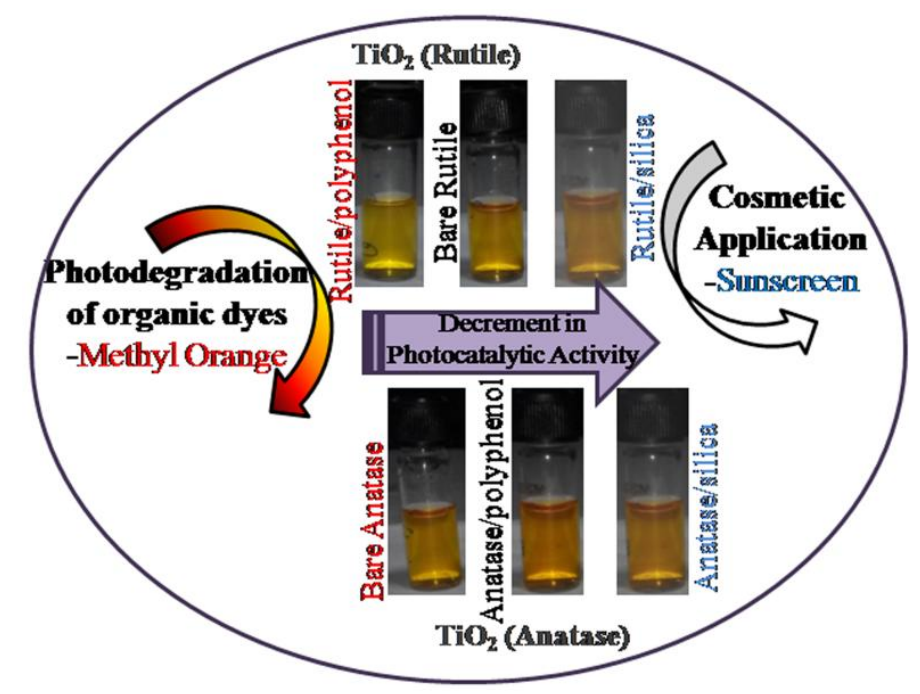

Scheme 4. Pictorial representation of the summarized results.

\section{Single column image, $500 \mathrm{dpi}$, image width $90 \mathrm{~mm}$}

\section{Conclusions}

In this study, nano-sized anatase and rutile $\mathrm{TiO}_{2}$ particles have been well synthesized by varying the post annealing temperatures and subsequently coated with inorganic (silica) and organic (green-tea) layer, separately by simple and efficient wet chemical method. Various characterization techniques affirm the formation of each of the phases of bare and core_shell $\left(\mathrm{TiO}_{2} \_\right.$silica/polyphenol) titania. The microscopy images confirm the thickness of coating with silica shell that was found to be about 80 and $20 \mathrm{~nm}$ over anatase and rutile nanocluster, respectively. The thickness of polyphenol shell was found to be $3 \mathrm{~nm}$ over anatase core. Surface modification of titania nanoparticles using organic moiety, greentea, has various advantages including biocompatibility, most abundant and cheaper which has not been studied in previous literature. The plausible mechanism of chemical interaction takes place with silica 
and polyphenol species on titania surface has been interpreted and correlated with FTIR spectroscopy. corresponding PL spectra. The results ascribe that silica coated -anatase and -rutile was found to be least photocatalytically active, ensuring their cosmetic application in sunscreens, whereas rutile_polyphenol and bare anatase discerns highest photocatalytic activity among their corresponding forms explore a wide research area including photodegradation of various dyes.

\section{Acknowledgements}

We thank the Director, NPL New Delhi, India for providing the necessary experimental facilities. Dr. A. Dhar, Mr. K. N. Sood, Mr. J. S. Tawale and Dr. S. K. Dhawan are gratefully acknowledged for providing the necessary instrumentation facilities for XRD, SEM, FTIR. The projects, NanoSHE (BSC0112) and DST (SR/NM/NS-97/2010), are gratefully acknowledged. One of the authors (PS) thanks DST for award of Women Scientist (SR/WOS-A/CS-70/2012). Electron microscopy was carried out in part in the Electron Microscopy Center at the Center for Nanoscale Materials, a U.S. Department of Energy Office of Science User Facility under Contract No. DE-AC02-06CH11357.

\section{References}

[1] D. A. H. Hanaor and C. C. Sorrell, Review of the anatase to rutile phase transformation, J. Mater. Sci., $2011,46,855$.

[2] L. Alibabaei, B. H. Farnum, B. Kalanyan, M. K. Brennaman, M. D. Losego, G. N. Parsons and T. J. Meyer, Atomic Layer Deposition of $\mathrm{TiO}_{2}$ on Mesoporous NanoITO: Conductive Core-Shell Photoanodes for Dye-Sensitized Solar Cells, Nano Lett., 2014, 14, 3255.

[3] J. Y. Ahn, J. H. Kim, K. J. Moon, S. D. Park and S. H. Kim, Synergistic Effects of the Aspect Ratio of $\mathrm{TiO}_{2}$ Nanowires and Multi-walled Carbon Nanotube Embedment for Enhancing Photovoltaic Performance of Dye-Sensitized Solar Cells, Nanoscale, 2013, 5, 6842.

[4] K. Nakata and A. Fujishima, $\mathrm{TiO}_{2}$ photocatalysis: Design and Applications, J. Photochem and photobiology C: Photochem. Rev., 2012, 13, 169.

[5] J. Gangwar, B. K. Gupta, S. K. Tripathi and A. K. Srivastava, Phase dependent thermal and spectroscopic responses of $\mathrm{Al}_{2} \mathrm{O}_{3}$ nanostructures with different morphogenesis, Nanoscale, 2015, 7, 13313. 
[6] X. Bai, L. Lv, X. Zhang and Z. Hua, Synthesis and photocatalytic properties of Palladium-loaded three dimensional flower-like anatase $\mathrm{TiO}_{2}$ with dominant $\left\{\begin{array}{lll}0 & 0 & 1\end{array}\right\}$ facets, J. Colloid Interface Sci., $2016,467,1$.

[7] T. Kamegawa, D. Yamahana and H. Yamashita, Graphene Coating of $\mathrm{TiO}_{2}$ Nanoparticles Loaded on Mesoporous Silica for Enhancement of Photocatalytic Activity, J. Phys. Chem. C, 2010, 114, 15049.

[8] T. Aarthi and G. Madras, Photocatalytic Degradation of Rhodamine Dyes with Nano- $\mathrm{TiO}_{2}$, Ind. Eng. Chem. Res., 2007, 46, 7.

[9] Y. R. Smith, A. Kar and V. Subramanian, Investigation of Physicochemical Parameters That Influence Photocatalytic Degradation of Methyl Orange over $\mathrm{TiO}_{2}$ Nanotubes, Ind. Eng. Chem. Res., $2009,48,10268$.

[10] L. Yu, J. Xi, M. D. Li, H. T. Chan, T. Su, D. 1. Phillips and W. K. Chan, The degradation mechanism of methyl orange under photo-catalysis of $\mathrm{TiO}_{2}$, Phys. Chem. Chem. Phys., 2012, 14, 3589.

[11] Z. D. Gao, Y. Qu, T. Li, N. K. Shreshtha and Y. Y. Song, Development of Amperometric Glucose Biosensor Based on Prussian Blue Functionlized $\mathrm{TiO}_{2}$ Nanotube Arrays, Sci. Rep., 2014, 4, 6891.

[12] L. Ren, Y. Li, J. Hou, X. Zhao and C. Pan, Preparation and Enhanced Photocatalytic Activity of $\mathrm{TiO}_{2}$ Nanocrystals with Internal Pores, ACS Appl. Mater. Inter., 2014, 6, 1608.

[13] C.Y. Flores, C. Diaz, A. Rubert, G. A. Benitez, M. S. Moreno, M. A. F. L. De Mele, R. C. Salvarezza, P. L. Schilardi and C. Vericat, Spontaneous adsorption of silver nanoparticles on $\mathrm{Ti} / \mathrm{TiO}_{2}$ surfaces. Antibacterial effect on Pseudomonas aeruginosa, J. Colloid Interface Sci., 2010, 350, 402.

[14] R. Verma, B. Mantri, Ramphal and A. K. Srivastava, Shape control synthesis, characterizations, mechanisms and optical properties of large scaled metal oxide nanostructures of $\mathrm{ZnO}$ and $\mathrm{TiO}_{2}$, $\mathrm{Adv}$. Mater. Lett., 2015, 6, 324.

[15] F. Turci, E. Peira, I. Corazzari, I. Fenoglio, M. Trotta and B. Fubini, Crystalline phase modulates the potency of nanometric $\mathrm{TiO}_{2}$ to adhere to and perturb the stratum corneum of porcine skin under indoor light, Chem. Res. Toxicol., 2013, 26, 1579 
[16] A. Jaroenworaluck, W. Sunsaneeyametha, N. Kosachan and R. Stevens, Characteristics of silica -coated $\mathrm{TiO}_{2}$ and its UV absorption for sunscreen cosmetic applications, Surf. Interface Anal., 2006, 38,473 .

[17] S. Kumar, S. Khanchandani, M. Thirumal and A. K. Ganguly, Achieving Enhanced Visible-LightDriven Photocatalysis Using Type-II $\mathrm{NaNbO}_{3} / \mathrm{CdS}$ Core/Shell Heterostructures, ACS Appl. Mater. Inter., $2014,6,13221$.

[18] Y. Li, W. Zhang, J. Niu and Y. Chen, Mechanism of Photogenerated Reactive Oxygen Species and Correlation with the Antibacterial Properties of Engineered Metal-Oxide Nanoparticles, ACS nano., 2012, 6, 5164.

[19] T. K. Kim, M. N. Lee, S. H. Lee, Y. C. Park, C. K. Jung and J. H. Boo, Development of surface coating technology of $\mathrm{TiO}_{2}$ powder and improvement of photocatalytic activity by surface modification, Thin solid films, 2005, 475, 171.

[20] X. Fu, L. A. Clark, Q. Yang and M. A. Anderson, Enhanced Photocatalytic Performance of TitaniaBased Binary Metal Oxides: $\mathrm{TiO}_{2} / \mathrm{SiO}_{2}$ and $\mathrm{TiO}_{2} / \mathrm{ZrO}_{2}$, Environ. Sci. Technol., 1996, 30, 647.

[21] T. A. Egerton, The Influence of Surface Alumina and Silica on the Photocatalytic Degradation of Organic Pollutants, Catalysts, 2013, 3, 338.

[22] I. A. Aloton, Advanced Oxidation of Textile Industry Dyes. In Advanced Oxidation Processes for Water and Wastewater Treatment; Parsons, S., Ed.; IWA Publishing: London, UK, 2004, 302.

[23] W. Wu, Q. He and C. Jiang, Magnetic Iron Oxide Nanoparticles: Synthesis and Surface Functionalization Strategies, Nanoscale Res. Lett., 2008, 3, 397.

[24] A. K. Srivastava, P. Bhatnagar, M. Singh, S. Mishra, P. Kumar, Y. Shukla and K. C. Gupta, Synthesis of PLGA nanoparticles of Tea Polyphenols and their Strong In Vivo Protective Effect Against Chemically Induced DNA Damage, Int. J. Nanomed., 2013, 8, 1451.

[25] M. C. Moulton, L. K. B. Stolle, M. N. Nadagouda, S. Kunzelman, S. M. Hussain and R. S. Varma, Synthesis, Characterization and Biocompatibility of “Green” Synthesized Silver Nanoparticles using Tea Polyphenols, Nanoscale, 2010, 2, 763.

[26] L. Schramm, Going Green: The Role of the Green Tea Component EGCG in Chemoprevention. J. Carcinog. Mutagen., 2013, 4. 
[27] S. M. Chacko, P. T. Thambi, R. Kuttan and I. Nishigaki, Beneficial effects of green tea: A literature review, Chin. Med., 2010, 5, 13.

[28] S. Hirun and P.D. Roach, A study of Stability of (-)-Epigallocatechin Gallate (EGCG) from Green Tea in a Frozen Product, Int. Food Res. J., 2011, 18, 1261.

[29] H. N. Graham, Green tea composition, consumption, and polyphenol chemistry, Prev. Med., 1992, 21, 334.

[30] S. P. J. N. Senanayake, Green tea extract: Chemistry, antioxidant properties and food applications - A review, J. Funct. Foods, 2013, 5, 1529.

[31] D. A. Balentine, S. A. Wiseman and L. C. Bouwens, The chemistry of tea flavanoids, Crit. Rev. Food Sci. Nutr., 1997, 37, 693.

[32] L. Xiao, M. Mertens, L. Wortmann, S. Kremer, M. Valldor, T. Lammers, F. Kiessling and S. Mathur, Enhanced In Vitro and In Vivo Cellular Imaging with Green Tea Coated Water-Soluble Iron Oxide Nanocrystals, ACS Appl. Mater. Inter., 2015, 7, 6530.

[33] Z. Hou, S. Sang and H. You, Mechanism of action of (-)-epigallocatechin-3-gallate: autooxidation-dependent inactivation of epidermal growth factor receptor and direct effects on growth inhibition in human esophageal cancer KYSE 150 cells, Cancer Res., 2005, 65, 8049.

[34] J. Y. Yoon, H. H. Kwon, S. U. Min, D. M. Thiboutot and D. H. Suh, Epigallocatechin-3-Gallate Improves Acne in Humans by Modulating Intracellular Molecular Targets and Inhibiting P. Acnes, J. Invest. Dermatol., 2013, 133, 429.

[35] Y. M. Li, H. Y. E. Chan, Y. Huang and Z. Y. Chen, Green tea catechins upregulate superoxide dismutase and catalase in fruit flies, Mol. Nutr. Food Res., 2007, 51, 546.

[36] B. Frei and J. V. Higdon, Proceedings of the Third International Scientific Symposium on Tea and Human Health: Role of Flavonoids in the Diet, Antioxidant Activity of Tea Polyphenols In Vivo: Evidence from Animal Studies, J. Nutr., 2003.

[37] Scientific Opinion, Scientific Opinion on the substantiation of health claims related to water and maintenance of normal physical and cognitive functions (ID 1102, 1209, 1294, 1331), maintenance of normal thermoregulation (ID 1208) and "basic requirement of all living things" (ID 1207) pursuant to Article 13(1) of Regulation (EC) No 1924/2006 and EFSA Panel on Dietetic Products, Nutrition and Allergies (NDA). EFSA Journal, 2011, 9, 2075. 
[38] Canadian Food Inspection Agency- Guide to Food Labelling and Advertising, 2010.

[39] Z. Wang, C. Fang and M. Megharaj, Characterization of Iron-Polyphenol Nanoparticles Synthesized by Three Plant Extracts and Their Fenton Oxidation of Azo Dye, ACS Sustainable Chem. Eng., 2014, 2 , 1022.

[40] K. Okada, N. Yamamoto, Y. Kameshima, A. Yasumori and K. J. D. MacKenzie, Effect of Silica Additive on the Anatase-to-Rutile Phase Transition, J. Am. Ceram. Soc., 2001, 84, 1591.

[41] Y. Guo, S. Yang, X. Zhou, C. Lin, Y. Wang and W. Zhang, Enhanced Photocatalytic Activity for Degradation of Methyl Orange over Silica-Titania, J. nanomater., 2011, doi: 10.1155/2011/296953.

[42] S. Hu, F. Li and Z. Fan, Preparation of $\mathrm{SiO}_{2}$-Coated $\mathrm{TiO}_{2}$ Composite Materials with Enhanced Photocatalytic Activity under UV Light, Bull. Korean Chem. Soc., 2012, 33, 1895.

[43] J. Das, F. S. Freitas, I. R. Evans, A. F. Nogueira and D. Khushalani, A Facile Nonaqueous Route for Fabricating Titania Nanorods and their Viability in Quasi-Solid-State Dye-Sensitized Solar Cells, J. Mater. Chem., 2010, 20, 4425.

[44] L. Pinho and M. J. Mosquera, Titania-Silica Nanocomposite Photocatalysts with Application in Stone Self-Cleaning, J. Phys. Chem. C., 2011, 115, 22851.

[45] M. Nussbaum and Y. Paz, Ultra-thin $\mathrm{SiO}_{2}$ Layers on $\mathrm{TiO}_{2}$ : Improved Photocatalysis by Enhancing Products’ Desorption, Phys. Chem. Chem. Phys., 2012, 14, 3392.

[46] S. M. Enggrob, S. Camilla, L. Zheshen and S. E. Gydesen, XPS and FT-IR investigation of silicate polymers, J. Mater. Sci., 2009, 44, 2079.

[47] J. Singh, A. Gusain, V. Saxena, A. K. Chauhan, P. Veerender, S. P. Koiry, P. Jha, A. Jain, D. K. Aswal and S. K. Gupta, XPS, UV-Vis, FTIR, and EXAFS Studies to Investigate the Binding Mechanism of N719 Dye onto Oxalic Acid Treated $\mathrm{TiO}_{2}$ and Its Implication on Photovoltaic Properties, J. Phys. Chem. C., 2013, 117, 21096.

[48] Z. R. Khan, M. S. Khan, M. Zulfequar and M. S. Khan, Optical and Structural Properties of ZnO Thin Films Fabricated by Sol-Gel Method, Mater. Sci. Appl., 2011, 2, 340.

[49] J. Gangwar, K. K. Dey, S. K. Tripathi, M. Wan, R. R. Yadav, Samta and A. K. Srivastava, NiObased Nanostructures with Efficient Optical and Electrochemical Properties for High-Performance Nanofluids, Nanotechnol., 2013, 24, 415705. 
[50] L. Ferretto and A. Glisenti, Surface Acidity and Basicity of a Rutile Powder, Chem. Mater., 2003, 15,1181

[51] J. Gangwar, B. K. Gupta, P. Kumar, S. K. Tripathi and A. K. Srivastava, Time- Resolved and Photoluminescence Spectroscopy of $\theta-\mathrm{Al}_{2} \mathrm{O}_{3}$ Nanowires for Promising Fast Optical Sensor Applications, Dalton Trans., 2014, 43, 17034.

[52] K. K. Dey, A. Kumar, R. Shankar, A. Dhawan, M. Wan, R. R. Yadav and A. K. Srivastava, Growth Morphologies, Phase Formation, Optical \& Biological Responses of Nanostructures of $\mathrm{CuO}$ and their Application as Cooling Fluid in High Energy Density Devices, RSC Adv., 2012, 2, 1387.

[53] X. Li, O. Niitsoo and A. Couzis, Electrostatically driven adsorption of silica nanoparticles on functionalized surfaces, J. Colloid Interface Sci., 2013, 394, 26.

[54] S. Gass, J. M. Cohen, G. Pyrgiotakis, G. A. Sotiriou, S. E. Pratsinis and P. Demokritou, Safer Formulation Concept for Flame-Generated Engineered Nanomaterials, ACS Sustainable Chem. Eng., $2013,1,843$.

[55] X. Li, O. Nittsoo and A. Couzis, Electrostatically assisted fabrication of silver-dielectric core/shell nanoparticles thin film capacitor with uniform metal nanoparticle distribution and controlled spacing, J. Colloid Interface Sci., 2016, 465, 333.

[56] M. K. Akhtar and S. E. Pratsinis, Dopants in Vapor-Phase Synthesis of Titania Powders, J. Am. Ceram. Soc., 1992, 75, 3408.

[57] A. Escudero and F. Langenhorst, Incorporation of $\mathrm{Si}$ into $\mathrm{TiO}_{2}$ Phases at High Pressure, Am. Mineral., 2012, 97, 524.

[58] T. G. Shutava, S. S. Balkundi, P. Vangala, J. J. Steffan, R. L. Bigelow, J. A. Cardelli, D. P. Oneal and Y. M. Lvov, Layer-by-Layer-Coated Gelatin Nanoparticles as a Vehicle for Delivery of Natural Polyphenols, ACS Nano., 2009, 3, 1877.

[59] J. B. Birks, Photophysics of Aromatic molecules. Wiley- Interscience, London 1970.

[60] C. Chen, J. Liu, P. Liu and B. Yu, Investigation of Photocatalytic Degradation of Methyl Orange by Using Nano-Sized ZnO Catalysts, Adv. Chem. Eng. Sci., 2011, 1, 9.

[61] Y. Yang, G. Wang, Q. Deng, D. H. L. Ng and H. Zhao, Microwave-Assisted Fabrication of Nanoparticulate $\mathrm{TiO}_{2}$ Microspheres for Synergistic Photocatalytic Removal of $\mathrm{Cr}(\mathrm{VI})$ and Methyl Orange, ACS Appl. Mater. Inter., 2014, 6, 3008. 
[62] P. Singh, O. P. Sinha, R. Srivastava, A. K. Srivastava, J. K. Bindra, R. P. Singh and M. N. Kamalasanan, Studies on Morphological and Optoelectronic Properties of MEH-CN-PPV:TiO ${ }_{2}$ Nanocomposites, Mater. Chem. Phys., 2012, 133, 317.

[63]U. Soni, P. Tripathy and S. Sapra, Photocatalysis from Fluorescence-Quenched CdSe/Au Nanoheterostructures: A Size-Dependent Study, J. Phys. Chem. Lett., 2014, 5, 1909.

[64]V. Etacheri, R. Roshan and V. Kumar, Mg-Doped ZnO Nanoparticles for Efficient Sunlight-Driven Photocatalysis, ACS Appl. Mater. Inter., 2012, 4, 2717.

[65] M. H. Lee, U. M. Patil, S. T. Kochuveedu, C. S. Lee and D. H. Kim, The Effect of $\mathrm{SiO}_{2}$ Shell on the Suppression of Photocatalytic Activity of $\mathrm{TiO}_{2}$ and $\mathrm{ZnO}$ Nanoparticles, Bull. Korean Chem. Soc., 2012, 33, 3767. 